\title{
Transformation of PVP coated silver nanoparticles in a simulated wastewater treatment process and the effect on microbial communities
}

\author{
Casey L Doolette ${ }^{1 *}$, Mike J McLaughlin ${ }^{1,2}$, Jason K Kirby ${ }^{2}$, Damien J Batstone ${ }^{3}$, Hugh H Harris ${ }^{4}$, Huoqing $\mathrm{Ge}^{3}$ \\ and Geert Cornelis ${ }^{5}$
}

\begin{abstract}
Background: Manufactured silver nanoparticles (AgNPs) are one of the most commonly used nanomaterials in consumer goods and consequently their concentrations in wastewater and hence wastewater treatment plants are predicted to increase. We investigated the fate of AgNPs in sludge that was subjected to aerobic and anaerobic treatment and the impact of AgNPs on microbial processes and communities. The initial identification of AgNPs in sludge was carried out using transmission electron microscopy (TEM) with energy dispersive X-ray (EDX) analysis. The solid phase speciation of silver in sludge and wastewater influent was then examined using X-ray absorption spectroscopy (XAS). The effects of transformed AgNPs (mainly Ag-S phases) on nitrification, wastewater microbial populations and, for the first time, methanogenesis was investigated.
\end{abstract}

Results: Sequencing batch reactor experiments and anaerobic batch tests, both demonstrated that nitrification rate and methane production were not affected by the addition of AgNPs [at $2.5 \mathrm{mg} \mathrm{Ag} \mathrm{L}^{-1}$ (4.9 g L L $^{-1}$ total suspended solids, TSS) and $183.6 \mathrm{mg} \mathrm{Ag} \mathrm{kg}^{-1}\left(2.9 \mathrm{~g} \mathrm{~kg}^{-1}\right.$ total solids, TS), respectively].

The low toxicity is most likely due to AgNP sulfidation. XAS analysis showed that sulfur bonded Ag was the dominant Ag species in both aerobic (activated sludge) and anaerobic sludge. In $\mathrm{AgNP}$ and $\mathrm{AgNO}_{3}$ spiked aerobic sludge, metallic Ag was detected ( 15\%). However, after anaerobic digestion, Ag(0) was not detected by XAS analysis. Dominant wastewater microbial populations were not affected by AgNPs as determined by DNA extraction and pyrotag sequencing. However, there was a shift in niche populations in both aerobic and anaerobic sludge, with a shift in AgNP treated sludge compared with controls. This is the first time that the impact of transformed AgNPs (mainly Ag-S phases) on anaerobic digestion has been reported.

Conclusions: Silver NPs were transformed to Ag-S phases during activated sludge treatment (prior to anaerobic digestion). Transformed AgNPs, at predicted future Ag wastewater concentrations, did not affect nitrification or methanogenesis. Consequently, AgNPs are very unlikely to affect the efficient functioning of wastewater treatment plants. However, AgNPs may negatively affect sub-dominant wastewater microbial communities.

Keywords: Silver nanoparticles, Silver sulfide, Wastewater treatment, STEM HAADF, Sequencing batch reactor, Nitrification, Microbial communities, Pyrotag sequencing, Silver speciation, XAS, Synchrotron, Biosolids

\footnotetext{
* Correspondence: casey.doolette@adelaide.edu.au

${ }^{1}$ School of Agriculture Food \& Wine, The University of Adelaide, PMB 1, Glen Osmond, SA 5064, Australia

Full list of author information is available at the end of the article
}

\section{() Chemistry Central}

(c) 2013 Doolette et al.; licensee Chemistry Central Ltd. This is an Open Access article distributed under the terms of the Creative Commons Attribution License (http://creativecommons.org/licenses/by/2.0), which permits unrestricted use, distribution, and reproduction in any medium, provided the original work is properly cited. 


\section{Background}

Rapid expansion of the nanotechnology industry has occurred over the previous decade. Manufactured nanomaterials (MNMs) encompass a variety of engineered materials, which can be divided into two groups for the sake of clarity: nano-sized particles (having at least two dimensions $<100 \mathrm{~nm}$ ) and secondly, materials that are not particulate but have nano-sized properties [1] (i.e. enhanced electronic, optical and chemical properties compared to the bulk material). Silver $\left(\mathrm{Ag}^{0}\right)$ nanoparticles (NPs) are the most widely used NPs in both consumer products and in medical applications [2]. The anti-bacterial properties that render AgNPs desirable may lead to increased risks to human and environmental health following release into the environment. The primary exposure pathway of AgNPs into the environment is via wastewater streams. Silver NPs may enter wastewater through the washing of $\mathrm{Ag}$ nano-containing textiles $[3,4]$ or plastics [5], or as a result of the use of nano-enhanced outdoor paints [6] and washing machines [7].

Several authors have investigated the fate of manufactured AgNPs in wastewater treatment plants (WWTPs) and have reported that the majority ( $>85 \%$ ) of AgNPs will be captured by biosolids (stabilised sludge) [5,8-11]. Accordingly, the predicted effluent concentrations of AgNP are very low (ng L ${ }^{-1}$ ) [11], whereas AgNP concentrations in sludge are predicted to be much higher (1-6 mg Ag kg-1) [11]. Both concentrations are likely to increase as the AgNP producing industry expands. Given this scenario, and the strong anti-bacterial effects of AgNPs, the stages of WWT that are likely to be affected by AgNPs are those that are dependent on the efficient functioning of microbes. Such stages are the aerobic activated sludge process and anaerobic digestion, which proceeds the former process in most WWTPs. There are very few studies that have investigated the impact of AgNPs on both processes in a sequential manner. Given that the transformation of AgNPs is likely during WWT $[8,12]$, it is crucial to understand at what stage transformation occurs so accurate risk assesments can be conducted using AgNPs in realistic forms.

During the activated sludge process, organic nitrogen and phosphorus are removed by various microbial communities. Several studies have investigated the impact of AgNPs on nitrification [9,13-15] and the effects on microbial populations that perform these processes $[16,17]$. However, results from nitrification studies are divergent with no inhibition [9] and varying degrees of inhibition $[14,15,18]$ observed on nitrification following AgNP addition in WWTPs or bioreactors at concentrations between 0.4 and $1 \mathrm{mg} \mathrm{Ag} \mathrm{L}^{-1}$.

The observed variation is most likely explained by the differences in input variables. A number of parameters differ between studies, all of which are known to influence
AgNP fate and toxicity e.g. intrinsic AgNP properties (size, coating), Ag concentration, sludge/wastewater properties (temperature, ionic strength (IS)), total suspended solids (TSS) and dissolved organic carbon, (DOC)), the type of sludge/wastewater used (realistic or artificial) and general experimental set-up (e.g. light intensity and wavelength which may cause photocatalytic reduction of $\mathrm{Ag}^{+}$and $\mathrm{AgNP}$ ).

The impact of AgNPs on anaerobic digestion has been less studied than that of nitrification. Methanogenic microorganisms are generally less sensitive to toxicants than aerobic communities. Silver NPs have been shown to have no effect on biogas and methane production at concentrations of 40 and $85 \mathrm{mg} \mathrm{Ag} \mathrm{L}^{-1}$, [19] and [13], respectively.

The bactericidal mechanism of AgNPs (and $\mathrm{Ag}^{+}$) to organisms is only partially understood and debate is ongoing as to the exact means of action [20]. However, there is concern that the same properties that render AgNPs useful as an antimicrobial may also impact WWTP performance by affecting sludge microbial populations. A high diversity of bacterial populations in WWTPs is crucial for successful removal of $\mathrm{BOD} / \mathrm{COD}, \mathrm{SS}$ and biological phosphorus and nitrogen.

The effects of AgNPs on sludge microbial communities have been investigated by a limited number of studies. The model nitrifying bacteria Nitrosomonas europae has been shown to be adversely affected by AgNPs at concentrations of $0.3 \mathrm{mg} \mathrm{Ag} \mathrm{L}{ }^{-1}$ [16] and $2 \mathrm{mg} \mathrm{Ag} \mathrm{L}^{-1}$ [17]. These are much higher Ag concentrations than would normally be found in the environment at present. The microbial communities found in anaerobic systems generally have a different response to toxicants compared to aerobic communities and are usually more sensitive to surface active and homeostatic inhibitors and less sensitive to metabolic inhibitors [21] . For example, at very high Ag concentrations $\left(40 \mathrm{mg} \mathrm{L}^{-1}\right.$ ), methanogenic communities (Methanosaeta and Methanomicrobiales) have been shown to be largely unaffected by AgNP exposure [19]. So far, however, there has only been analysis of dominant microbes, through relatively insensitive techniques such as $\mathrm{qPCR}$, without assessing the impact on subdominant populations as allowed by next generation techniques such as t-RFLP.

This study was undertaken to (i) investigate the effects of Ag and polyvinylpyrrolidone coated (PVP) AgNPs on organic nitrogen removal from wastewater (nitrification) (ii) examine the fate of $\mathrm{Ag}^{+}$and AgNPs during various stages of WWT (iii) investigate the effects of transformed $\mathrm{Ag}^{+}$and AgNP on anaerobic digestion efficiency, and (iv) to determine if dominant and niche microbial community structures in aerobic and anaerobic sludge are impacted by exposure to transformed $\mathrm{Ag}^{+}$and AgNPs using pyrosequencing. 


\section{Results and discussion}

Silver nanoparticle partitioning in the sequence batch reactor process

Measured concentrations of $\mathrm{Ag}$ as a function of time in the mixed liquor and effluent are shown in Figure 1. Silver concentrations in the mixed liquor of each sequencing batch reactor (SBR) increased non-linearly during the $10 \mathrm{~d}$ aerobic stage. The cumulative concentration of $\mathrm{Ag}$ in the mixed liquor was less than the nominal value (taking into account Ag losses with effluent) possibly due to losses of mixed liquor that occurred during sampling for nitrification analysis and during decanting. In addition, Ag losses may have been due to sorption/complexation of Ag/AgNPs onto SBR tubing and container walls.

The effluent concentrations of Ag in the SBR spiked with AgNPs varied from $0.5 \mu \mathrm{g} \mathrm{L} \mathrm{L}^{-1}$ (day 5) to $7.7 \mu \mathrm{g} \mathrm{L} \mathrm{L}^{-1}$ (day 1 ). This corresponds to between $0.1 \%$ (for days $5-8$ ) and $5.4 \%$ (day 1 ) of the total amount of $\mathrm{Ag}$ in the mixed liquor (nominal) being removed with the effluent. Similarly, in the $\mathrm{Ag}^{+}$dosed SBR, between $0.1 \%$ (days $5-8$ ) and $1.1 \%$ (day 1) of Ag was released with the effluent. Surprisingly, the Ag concentration range of the effluents collected from the control SBR $\left[0.3 \mu \mathrm{g} \mathrm{L}{ }^{-1}\right.$ (days 2 and 7) to $4.7 \mu \mathrm{g} \mathrm{L}{ }^{-1}$ (day 8)] were within the same range as the effluents collected from the $\mathrm{Ag}^{+}$dosed SBR; $0.3 \mu \mathrm{g} \mathrm{L}{ }^{-1}$ (days 7 and 8) to $4.7 \mu \mathrm{g} \mathrm{L} \mathrm{L}^{-1}$ (day 4). This can be explained by background Ag concentrations in the influent wastewater $(15.0 \pm 7.6 \mu \mathrm{g}$ $\mathrm{Ag} \mathrm{\textrm {L } ^ { - 1 }}$ ) and activity sludge mixed liquor. Overall, the average ( $n=8$ days, where day 1 and 8 are the first and last days of $\mathrm{Ag}$ addition) percentages of $\mathrm{Ag}$ in the effluents \pm standard deviation (SD) were $0.8 \pm 0.1 \%, 0.4 \pm$ $0.4 \%$, and $2.0 \pm 2.8 \%$, for the AgNP, $\mathrm{Ag}^{+}$and control SBRs, respectively. There is large variation in the control as the background Ag concentrations were close to inductively coupled plasma-mass spectrometry (ICP-MS) instrumental detection limits $(0.05 \mu \mathrm{g} / \mathrm{L})$. The results demonstrate that the majority of Ag spiked into SBRs, as AgNPs or ionic $\mathrm{Ag}^{+}$ was retained by the sludge.

The partioning results in this study are in agreement with previous studies which have shown that the majority of AgNPs in wastewater will be partitioned to the sludge fraction following wastewater treatment [8-10]. However, the degree to which AgNPs are removed from wastewater has varied between each study. In a pilot WWTP experiment [8], 2.5\% of spiked Ag (added as AgNPs stabilised by polyoxyethylene fatty acid ester) was released from the WWTP with the effluent, whereas in a $15 \mathrm{~d}$ simulated SBR experiment (0.9 L working volume), citrate coated AgNPs were found to be completely removed from the wastewater [9]. In the literature, the lowest removals of AgNPs from wastewater $(88 \pm 4 \%)$ were recorded from a SBR experiment using synthetic wastewater and AgNPs with an unspecified polymer coating [10].
The observed variations in removal efficiency of AgNPs from the above studies may be due to a number of factors including; the intrinsic properties of the NP (i.e. size, surface charge and capping agent) which in turn are influenced by additional parameters (e.g. mixed liquor $\mathrm{pH}$, chloride concentrations, etc.), method of spiking [16] and perhaps most importantly, the characteristics of the influent wastewater and activated sludge. The TSS content of the influent and activated sludge determines the initial mixed liquor TSS. In the current study, the TSS content $\left(4.5 \pm 0.6 \mathrm{~g} \mathrm{TSS} \mathrm{L}^{-1}\right)$ was greater than that used in other studies [8-10](3, 2.4 and $1.8 \mathrm{~g} \mathrm{TSS} \mathrm{L}^{-1}$, respectively). This may explain the high removal efficiency of AgNPs from wastewater (> 99\%) which we observed in this study. Most NPs in WWTP sludge is likely to be heteroaggregated with bacteria [10,22-24] but NPs can also be associated with iron oxides or other inorganic particles [23].

At the conclusion of the SBR experiment, sludge Ag concentrations were 418, 168 and $6 \mathrm{mg} \mathrm{Ag} \mathrm{kg}^{-1}$ (TS) for the AgNP, $\mathrm{Ag}^{+}$and control treatments, respectively. The high concentration of Ag in the AgNP sludge is due to the higher Ag concentrations in the AgNP spiking suspensions (mean $\pm \mathrm{SD} ; 39 \pm 6 \mathrm{mg} \mathrm{Ag} \mathrm{L} \mathrm{L}^{-1}, \mathrm{n}=11$ ) compared to the $\mathrm{Ag}^{+}$solution (mean $\pm \mathrm{SD} ; 19.4 \pm 0.1 \mathrm{mg}$ $\left.\mathrm{Ag} \mathrm{L}^{-1}, \mathrm{n}=3\right)$; rather than a greater removal of Ag from the wastewater fraction. Due to logistical limitations, the concentrations of each AgNP suspension could not be determined before spiking as the homogenised NP suspensions degrade after $24 \mathrm{~h}$.

The Ag concentrations of the prepared AgNP suspensions were higher than we had previously achieved and therefore higher than the nominal spiking concentration. The total mass of Ag added to the AgNP and $\mathrm{Ag}^{+}$SBRs, not including background inputs from effluent, was $12.7 \mathrm{mg}$ and $6.4 \mathrm{mg}$, respectively. The results from the SBR experiments show that the majority of AgNP is partitioned to the solid phase.

\section{Silver nanoparticle transformation during the sequence batch reactor process as determined using STEM analysis} Numerous bright regions were observed in sludge collected from the AgNP dosed SBR (Figure 2a) using scanning transmission electron microscopy (STEM) analysis in highangle annular dark field (HAADF) mode. Further analysis of the bright spots by energy dispersive X-ray analysis (EDX) confirmed that these regions contained Ag (Figure 3). The STEM image shows aggregates of Ag approximately $100-120 \mathrm{~nm}$ in diameter (Figure $2 \mathrm{~b}$ ). The higher magnification image (Figure $2 \mathrm{~b}$.) shows that each aggregate appears to consist of smaller agglomerated spherical NPs of approximately $40-50 \mathrm{~nm}$ diameter. EDX analysis of this agglomerate showed that each region consisted of $\mathrm{Ag}$ and $\mathrm{S}$ with varying ratios. Two regions in the $100-200 \mathrm{~nm}$ aggregate had a $\mathrm{Ag} / \mathrm{S}$ ratio of 2:1 (spot 1 and 2), whereas 


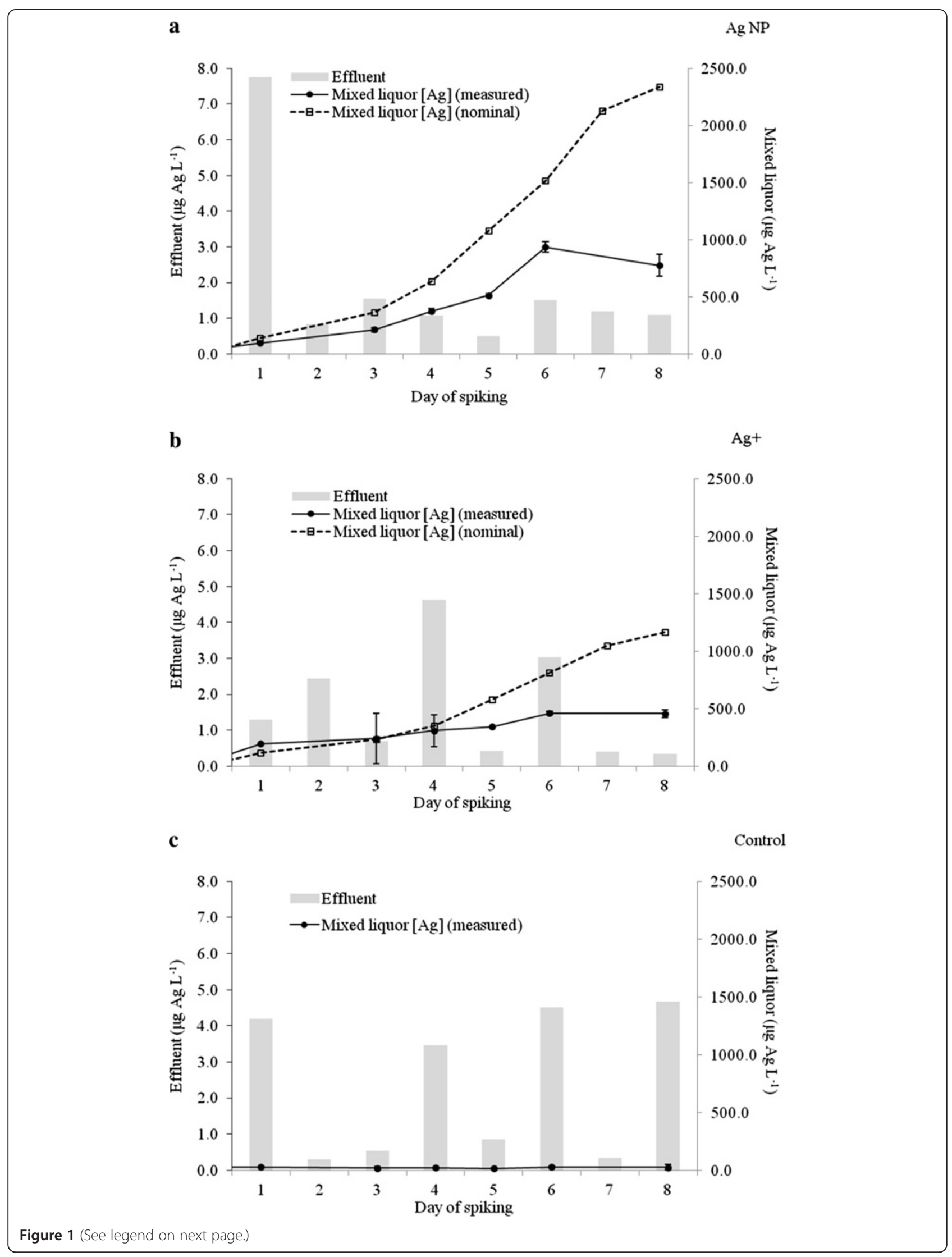


(See figure on previous page.)

Figure 1 Silver concentrations in the effluent and the total mass of $\mathrm{Ag}$ added to the AgNP dosed (a); $\mathrm{Ag}^{+}$dosed (b); and, control (c) SBRs. Less than $1 \%$ of added Ag was found in the effluent. Nominal Ag concentrations were calculated from measured Ag spiking solution concentrations. Error bars represent one standard deviation $(n=3)$.

one region contained $\mathrm{Ag} / \mathrm{S}$ with a $1: 1$ ratio (spot 3) (Figure 3). The specific cause of NP aggregation requires further investigation. However, it may be attributable to a number of factors including the ionic strength of the mixed liquor and the presence of organic chlorides and minerals. Ionic strength in domestic wastewater is typically $<0.1 \mathrm{M}$, whereas in anaerobic digesters IS is $<1 \mathrm{M}$, this may cause NP homocoagulation (see Additional file 1: Table SI.2 for wastewater elemental analysis). Conversely heterocoagulation of NPs may arise from the interaction of AgNPs with organic chlorides and minerals.

Silver sulfide (as $\alpha-\mathrm{Ag}_{2} \mathrm{~S}$ ) in the nano- size range has previously been identified in sludge $[8,12]$; however, to determine the crystal phase of the nano-sized particles in this study, further crystallographic investigation is required. At temperatures $<173^{\circ} \mathrm{C}$, the monoclinic crystalline form of silver sulfide $\left(\alpha-\mathrm{Ag}_{2} \mathrm{~S}\right)$ dominates (acanthite). For this phase to exist in the current study, $\operatorname{Ag}(0)$ in the original AgNP must be first oxidised to $\mathrm{Ag}^{+}[25,26]$.

A recent study [25] provided evidence for the direct conversion of AgNPs to $\mathrm{Ag}_{2} \mathrm{~S}$ via an oxysulfidation mechanism which was dependent on the presence of small amounts of dissolved $\mathrm{O}_{2}$. In the SBR experiment, residual $\mathrm{O}_{2}$ did remain during the $110 \mathrm{~min}$ anoxic phase. Interestingly, EDX analysis showed that $\mathrm{S}$ was present in all nanosized Ag particles identified in the sludge despite the very short anoxic phase relative to the sulfidation reaction times of AgNPs (i.e. $>5 \mathrm{~h}$ [8]). Given the very short anoxic phase (105 $\mathrm{min})$, the results suggest that sulfidation of AgNPs in mixed liquor may occur more rapidly than previously shown. Alternatively, AgNP sulfidation in the SBR may have been a gradual process that occurred during successive anoxic phases; i.e. during each anoxic phase a fraction of AgNPs may have been sulfidised until all AgNPs were sulfidised. This pathway is unlikely though as 'fresh' AgNPs were added each day.

To the best of our knowledge, the results are the first to identify sulfidised Ag nanosized aggregates in aerobically generated sludge. A previously study that identified $\mathrm{Ag}_{2} \mathrm{~S}$ in 'aerobic' mixed liquor of a pilot WWTP was not truly representative of an aerated sample because the mixed liquor was first subjected to anaerobic treatment [8]. We therefore suggest that $\mathrm{Ag}_{2} \mathrm{~S}$ identified in that aerobic sludge would have been produced during the initial anaerobic treatment because once formed, $\mathrm{Ag}_{2} \mathrm{~S}$ is very resistant to oxidation and dissolution of $\mathrm{Ag}$ (analogous to other metal oxides [27]). Overall, the results show that in WWTPs, the sulfidation of AgNPs may occur during activated sludge treatment prior to anaerobic digestion.

\section{Silver speciation in wastewater, activated sludge and anaerobic digestate as determined by synchrotron studies}

Principal component analysis (PCA) and target transformation identified six standard compounds suitable for the fitting of $\mathrm{Ag}$ in sludge samples: $\mathrm{Ag}_{2} \mathrm{~S}$ NPs, Ag-acetate,
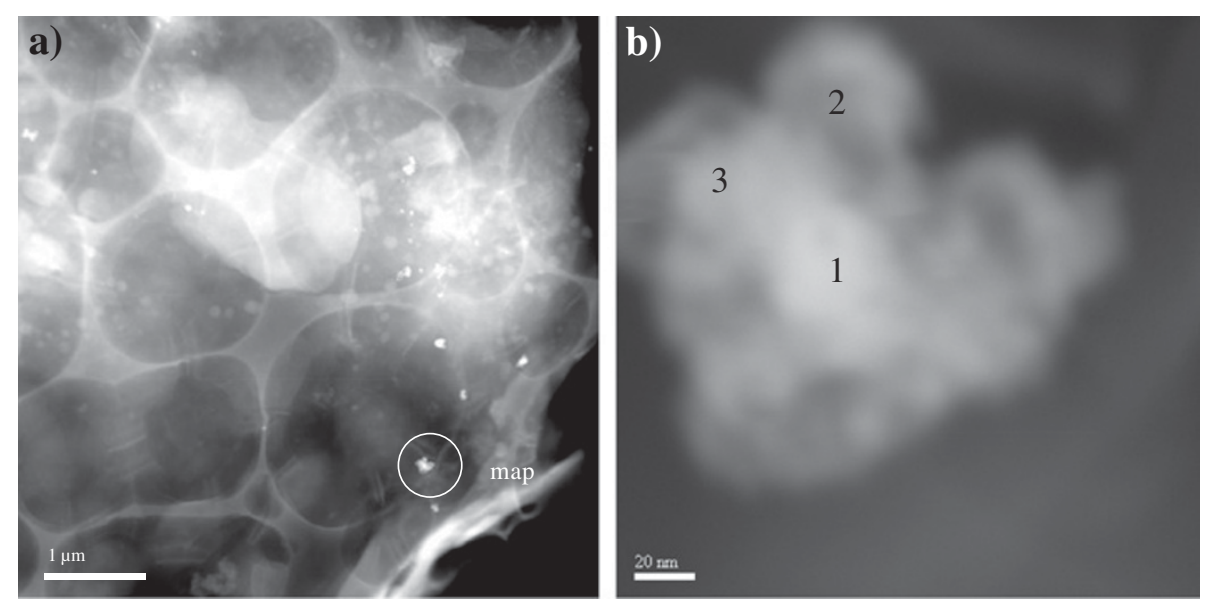

Figure 2 Characterisation of transformed Ag nanoparticles in aerobic sludge samples using STEM-HAADF. (a) STEM-HAADF image of a typical NP aggregate containing sulfidised nanoscale Ag particles. The bright aggregates are indicative of high Z elements (b) STEM-HAADF image of a typical Ag aggregate, particles 1-3 were characterised using energy dispersive X-ray (EDX) analysis (see Figure 3). The sludge sample was collected from the AgNP spiked SBR at the end of the experiment SBR experiment. 

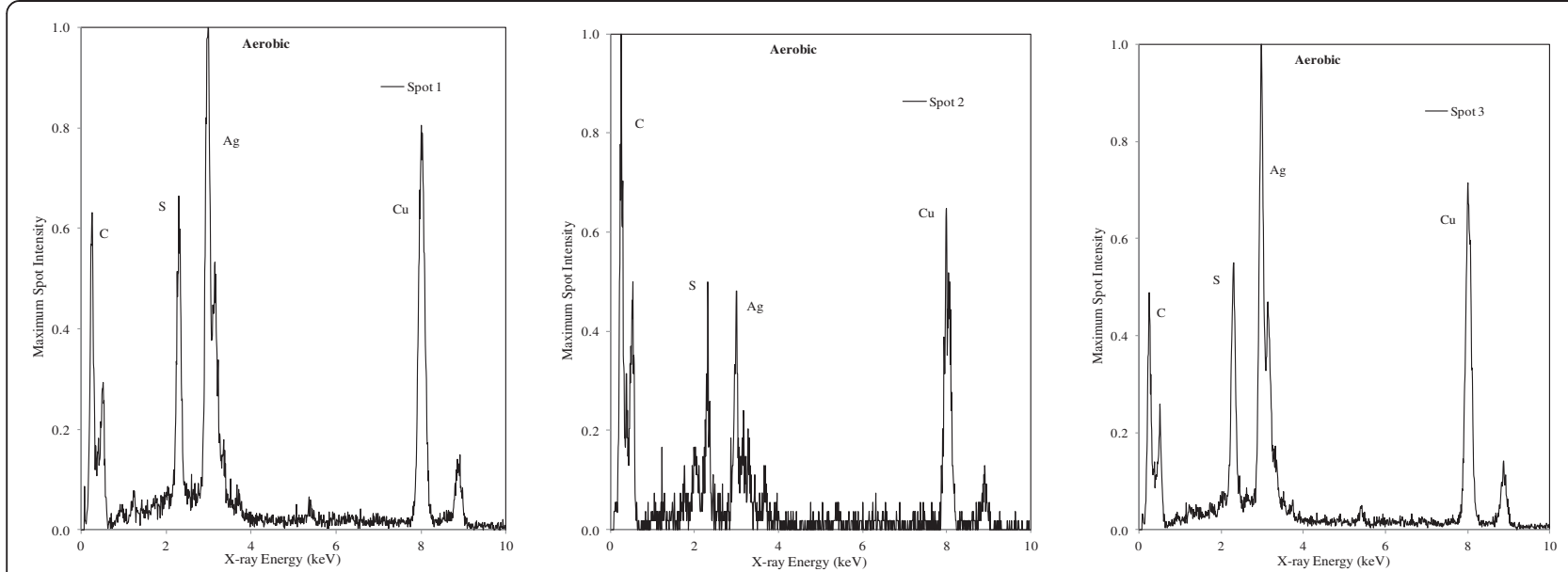

Figure 3 Energy dispersive X-ray (EDX) spectra of sulfidised silver nanoparticles in aerobic sludge. Spectra were collected from the specific spots indicated in Figure $2 b$.

Ag-glutathione (Ag-GSH), Ag-thiosulfate, $\mathrm{Ag}$-foil $\left(\mathrm{Ag}^{0}\right)$ and $\mathrm{Ag}_{2} \mathrm{~S}$ (Figure 4). Examination of the XANES spectra of the six target compounds (Figure 4) showed that $\mathrm{Ag}_{2} \mathrm{~S} \mathrm{NP}$ and $\mathrm{Ag}$-GSH were very similar (also see XANES difference spectra Additional file 1: Figure SI.2b). Therefore, for these Ag standards, their percentage contributions to the sample model fits were combined (Table 1). The two remaining Ag-S models (Ag-GSH and Ag-thiosulfate) are not easily distinguishable from each other by visual inspection of the spectra; however, examination of the difference spectra does show considerable variation (Additional file 1: Figure SI.2b). Furthermore, the identities of Ag-GSH and Ag-glutathione (Ag-GSH) standards were confirmed by EXAFS analysis (data not shown).

The Ag K-edge XANES spectra of all sludge samples and samples from the wastewater experiment are shown in Figure 4 together with the six references that were used in the linear combination fitting (LCF). The LCF analysis provided good fits to all experimental data (Additional file 1: Figure SI.5). Results show that the dominant $\mathrm{Ag}$ species identified in all aerobic and anaerobic sludges was Ag bonded with sulfur (S). The contributions of each standard varied between the different Ag treatments $\left(\mathrm{Ag}^{+}\right.$vs. $\left.\mathrm{AgNP}\right)$ and also between each treatment process (aerobic vs anaerobic) (Table 1). The exception to this was in the wastewater samples.

The two spectra of AgNP dosed sludge shows that AgNPs were completely transformed during the SBR experiment and again during anaerobic digestion (Figure 4, Table 1). To the best of our knowledge this is the first time that sulfidation of AgNPs has been reported in aerated sludge. The aerobic sample (labelled ANP) was dominated (85\%) by sulfidised Ag species with minor amounts of elemental Ag (15\%). However, in the anaerobic sample (NNP), elemental Ag was not a significant component. The absence of $\operatorname{Ag}(0)$ in the anaerobic AgNP sample is supported by analysis of the corresponding EXAFS spectra (Additional file 1: Figure SI.7) where Ag - Ag bonding was not detected (Table 2).

In the anaerobic AgNP treated sludge, bulk $\mathrm{Ag}_{2} \mathrm{~S}$ was detected (13\%) whereas in the aerobic sludge it was not detected by XAS. This suggests that the anaerobic digestion process in WWTPs may be vital for the conversion of nano-sized aggregates to bulk forms. The spectral differences that were observed between bulk $\mathrm{Ag}_{2} \mathrm{~S}$ and $\mathrm{Ag}_{2} \mathrm{~S}$ NPs are a common feature when comparing the XANES spectra of NPs and the bulk. Such effects have been reported for numerous NPs, including $\mathrm{Au}, \mathrm{CdS}$, $\mathrm{ZnO}$ and $\mathrm{Fe}_{2} \mathrm{O}_{3}$ NPs [28-30]).

Similar sulfidation trends are apparent for the $\mathrm{Ag}^{+}$ dosed sludge; the major components of the aerobic and anaerobic sludges were Ag-S coordinated species ( $80 \%$ and $86 \%$, respectively). This was supported by EXAFS analysis which identified Ag- $\mathrm{S}$ bonding in each sludge sample (Table 2). The major solid phase speciation changes between aerobic and anaerobic AgNP dosed sludge was the decrease in $\operatorname{Ag}(0)$ (15\% to 0\%) and $\mathrm{Ag}_{2} \mathrm{~S} \mathrm{NP}(40 \%$ to $14 \%)$ and the subsequent increase in bulk $\mathrm{Ag}_{2} \mathrm{~S}$ (8\% to 30\%). It is most likely that metallic $\mathrm{Ag}$ was produced in the $\mathrm{Ag}^{+}$dosed aerobic sludge by photocatalytic reduction of $\mathrm{AgNO}_{3}$, or alternatively by reducing agents in the mixed liquor (e.g. hydrogen sulfide, glucose).

Comparison of the XANES spectra for anaerobic $\mathrm{Ag}^{+}$ spiked sludge and anaerobic AgNP sludge shows only minor differences. However, much greater differences were found between the aerobic AgNP treated sludge and the anaerobic $\mathrm{Ag}^{+}$sludge (Additional file 1: Figure SI.6).

Silver acetate was identified as a significant component (as determined by the size of the residual following least squares refinement of the model compounds during LCF) in the XANES fitting of the anaerobic AgNP sludge (8\%) but not in the aerobic sample. The structure of this 


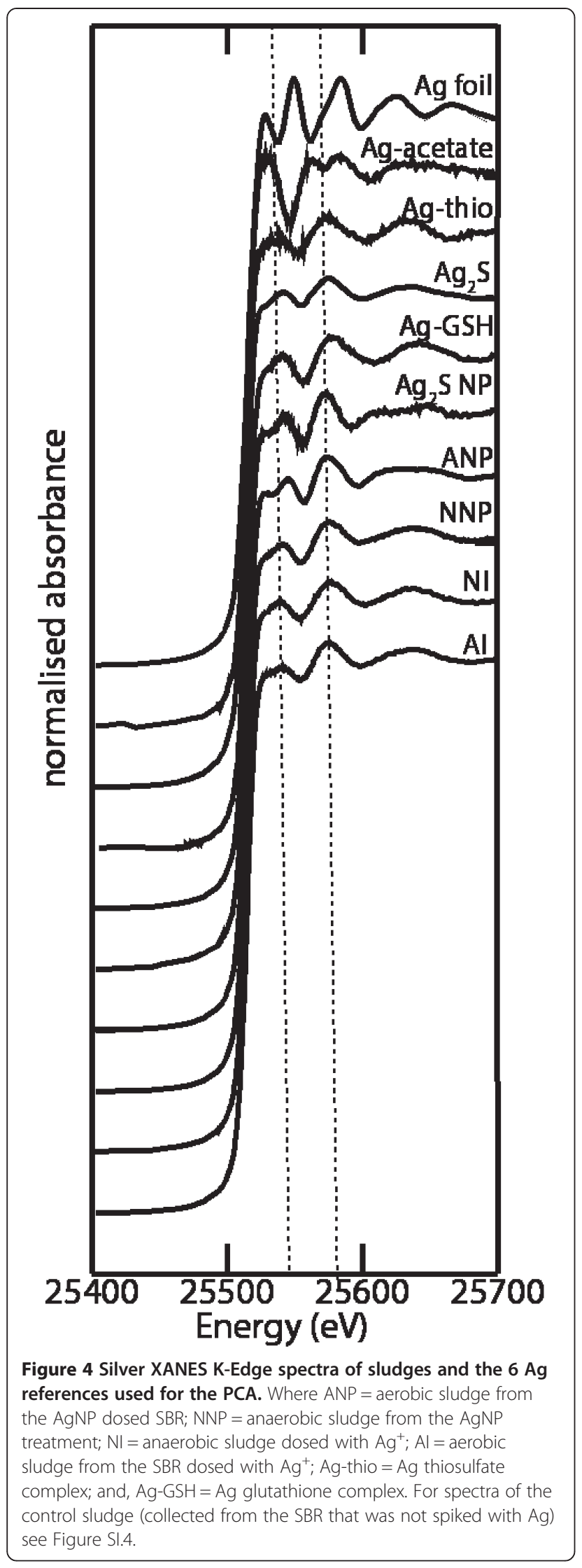

standard was not verified by other methods, however, the spectra is significantly different from the $\mathrm{Ag}-\mathrm{S}$ and $\mathrm{Ag}(0)$ standards (Figure 4 \& Additional file 1: Figure SI.2b) to be confident that Ag-carboxyl groups are present in the anaerobic sludge sample. In samples where Ag-acetate was detected as a significant component (Table 1), re-fitting the spectra with $\mathrm{Ag}_{2} \mathrm{O}$ produced a poorer quality fit with larger $R^{2}$ values. Furthermore, when Ag-acetate was excluded from the model, this led to an increase in the fit residuals (see Additional file 1: Table SI. 3 for increased residual values).

Overall the majority of Ag in the AgNP dosed aerobic and anaerobic sludges was sulfidised (85\% and 92\%, respectively). The results are in agreement with previous studies that have shown sulfidation of AgNPs in sludge $[8,12]$ and highlights the importance of considering $\mathrm{Ag}$ speciation in determining the fate and toxicity of AgNPs in terrestrial environments.

The speciation of AgNPs in influent wastewater has not been previously investigated. Based on Ag K-edge XANES results, the results demonstrate that the absence of activated sludge in influent wastewater had a considerable effect on AgNP transformation (Table 1). There was complete transformation of $\mathrm{AgNPs}$ to $\mathrm{Ag}(0)$ for all wastewater samples; no other species was identified as a significant component in the fit model. Furthermore, there were only subtle differences in the spectra for samples collected initially (4 min after spiking) and after 3.5 h. (Additional file 1: Figure SI.4). The results suggest that when PVP coated AgNPs enter wastewater, their polymer coating will be quickly modified or lost, and aggregation will occur. Additional analysis using the PVP AgNP reference in place of metallic $\operatorname{Ag}(0)$ as a target component, produced a poorer fit with a greater residual (3.14 cf. 0.72). It should be noted that the PVP coating of the AgNPs used in the experiments has not been fully characterised (i.e. coating thickness), so this effect may not be observed for all PVP coated NPs. However, it can be concluded that that when AgNPs enter WWTPs, the polymer surface coating may already be modified and AgNPs will no longer be nano in size. The size increase may be caused by a number of factors, including heterocoagulation with natural colloids (e.g. dissolved organic matter and iron and manganese oxyhydroxides) and aggregation due to high ionic strength of the wastewater.

\section{Effect of silver nanoparticles on nitrification}

The ammonium $\left(\mathrm{NH}_{4}^{+}\right)$and nitrate/nitrite $\left(\mathrm{NO}_{\mathrm{x}}\right)$ profiles of each SBR are illustrated in Figures $5 \& 6$. There was near complete removal of $\mathrm{NH}_{4}^{+}(>99 \%)$ observed from each SBR during each cycle. It should be noted that for the cycle analysed on day 2 for the AgNP dosed SBR only $70 \%$ of $\mathrm{NH}_{4}^{+}$was removed. In a similar SBR experiment, 
Table 1 Linear combination fitting analysis of XANES spectra of sludges collected from the SBRs (aerobic), sludges after anaerobic batch tests (anaerobic) and from the short term wastewater experiment

\begin{tabular}{|c|c|c|c|c|c|c|}
\hline Sample & $\mathrm{Ag}_{2} \mathrm{~S}$ & $\mathrm{Ag}_{2} \mathrm{~S} \mathrm{NP}+\mathrm{Ag}-\mathrm{GSH}$ & $\mathrm{Ag}(0)$ & Ag-acetate & Ag-thiosulfate & Residual \\
\hline \multicolumn{7}{|c|}{$\underline{\text { Aerobic sludges }}$} \\
\hline Control & & $40(5)$ & $20(3)$ & $19(3)$ & $23(4)$ & 0.350 \\
\hline $\mathrm{Ag}^{+}$ & $8(2)$ & $72(8)$ & $6(0.9)$ & $14(0.9)$ & & 0.029 \\
\hline AgNP & & $85(4)$ & $15(4)$ & & & 0.022 \\
\hline \multicolumn{7}{|c|}{ Anaerobic sludges } \\
\hline Control & $39(9)$ & $24(7)$ & & $27(4)$ & $11(6)$ & 0.549 \\
\hline $\mathrm{Ag}^{+}$ & $30(1)$ & $56(2)$ & & $13(0.7)$ & & 0.015 \\
\hline AgNP & $13(2)$ & $78(6)$ & & $8(0.8)$ & & 0.030 \\
\hline
\end{tabular}

Wastewater Experiment

$4 \min$

The proportion of species are presented as percentages with the estimated standard deviation (SD) in parentheses. For the $\mathrm{Ag}_{2} \mathrm{~S} \mathrm{NP}+\mathrm{Ag}-\mathrm{GSH}$ column, the SD is the sum of the individual SD's from each species. The control sludge was collected from the SBR that was not spiked with Ag.

slight inhibition of nitrifying organisms by AgNPs

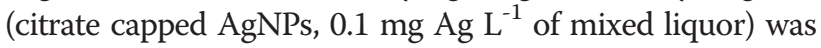
also observed on the first day of Ag addition [9]. However, the current results are most likely due to unexpected incomplete mixing of mixed liquor. In the cycle immediately following, complete mixing was resumed, and thus complete $\mathrm{NH}_{4}^{+}$removal would be expected as occurred in the other SBRs for day 2. At the beginning of the aeration phase the highest concentrations of $\mathrm{NH}_{4}^{+}$were observed,

Table 2 Structural parameters of sludges and standards derived from EXAFS analysis

\begin{tabular}{|c|c|c|c|c|}
\hline Sample & Shell & $\mathrm{CN}^{\mathrm{a}}$ & $\mathbf{R}^{\mathbf{b}}$ & $\sigma^{2 c}$ \\
\hline \multicolumn{5}{|l|}{$\underline{\text { Aerobic sludges }}$} \\
\hline $\mathrm{Ag}+$ & $\mathrm{Ag}-\mathrm{S}$ & 2.0 & 2.55 & 0.007 \\
\hline \multirow[t]{4}{*}{ AgNP } & $\mathrm{Ag}-\mathrm{S}$ & 1.6 & 2.51 & 0.005 \\
\hline & $\mathrm{Ag}-\mathrm{Ag}$ & 2.4 & 2.89 & 0.005 \\
\hline & $A g-A g$ & 3.0 & 3.09 & 0.006 \\
\hline & $\mathrm{Ag}-\mathrm{Ag}$ & 2.4 & 4.98 & 0.003 \\
\hline \multicolumn{5}{|c|}{$\underline{\text { Anaerobic sludges }}$} \\
\hline $\mathrm{Ag}^{+}$ & $\mathrm{Ag}-\mathrm{S}$ & 2.0 & 2.48 & 0.008 \\
\hline AgNP & $\mathrm{Ag}-\mathrm{S}$ & 2.0 & 2.51 & 0.005 \\
\hline \multicolumn{5}{|l|}{ References } \\
\hline \multirow[t]{2}{*}{$\mathrm{Ag}_{2} \mathrm{SNP}$} & $\mathrm{Ag}-\mathrm{S}$ & 1.5 & 2.52 & 0.004 \\
\hline & $\mathrm{Ag}-\mathrm{Ag}$ & 3.0 & 3.06 & 0.007 \\
\hline Ag-foil & $\mathrm{Ag}-\mathrm{Ag}$ & 12.0 & 2.86 & 0.001 \\
\hline \multirow[t]{2}{*}{$\mathrm{Ag}-\mathrm{GSH}$} & $\mathrm{Ag}-\mathrm{S}$ & 2.0 & 2.49 & 0.003 \\
\hline & $\mathrm{Ag}-\mathrm{Ag}$ & 1.0 & 3.03 & 0.007 \\
\hline Ag-thiosulfate & $\mathrm{Ag}-\mathrm{Ag}$ & 1.0 & 2.52 & 0.002 \\
\hline
\end{tabular}

with low variation between each SBR. The maximum concentrations were recorded on different days for the control (day 4; $24.5 \mathrm{mg} \mathrm{NH}_{4}^{+} \mathrm{L}^{-1}$ ), AgNP (day 6; $20.8 \mathrm{mg} \mathrm{NH}_{4}^{+} \mathrm{L}^{-1}$ )

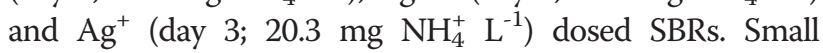
amounts of nitrite $\left(\mathrm{NO}_{2}^{-}\right)$were produced in the reactors, however, even during the cycles that had the highest concentrations, $\mathrm{NO}_{2}^{-}$was completely converted to nitrate $\left(\mathrm{NO}_{3}^{-}\right)$before the end of the phase.

Nitrification rates were calculated using linear regression over time for two complete cycles on days 8 and 9 and normalised for TSS content (Table 3 ). The rates were calculated from the initial reduction of $\mathrm{NH}_{4}^{+}$at the beginning of the aeration phase (Figure 5). Nitrification occurred rapidly in the first $50-60 \mathrm{~min}$ of the aerobic phase, and as a result the linear regression is based on 3 time measurements. To support these results, an on-line $\mathrm{NHx}$ autoanalyser (YSI, USA) was also used on days 8 and 9 to measure $\mathrm{NH}_{4}^{+}$concentrations in the AgNP and $\mathrm{Ag}^{+}$dosed SBRs, respectively (Additional file 1: Figure SI.1). A comparison of the nitrification rates calculated from both analysis methods shows comparable results (Table 3); confirming the accuracy of the chemical data. Probe determined $\mathrm{NH}_{4}^{+}$concentrations are between $4.5 \mathrm{mg} \mathrm{L}^{-1}$ and $5.4 \mathrm{mg} \mathrm{L}^{-1}$ lower than those obtained from chemical analysis (Table 3 ). This may be due to the close proximity of the probe to the aeration stone in the SBR. Alternatively, the lower $\mathrm{pH}$ of the mixed liquor compared to the calibration solutions may have caused a shift of the $\mathrm{NH}_{4}^{+}$ equilibrium $\left(\mathrm{NH}_{3}+\mathrm{H}^{+} \rightleftharpoons \mathrm{N} \mathrm{H}_{4}^{+}\right)$to the left, decreasing the concentration of $\mathrm{NH}_{4}^{+}$. There was very limited variation in the nitrification rates of all SBRs.

Several studies have investigated the effect of AgNPs on nitrification in WWTPs, but results are conflicting 

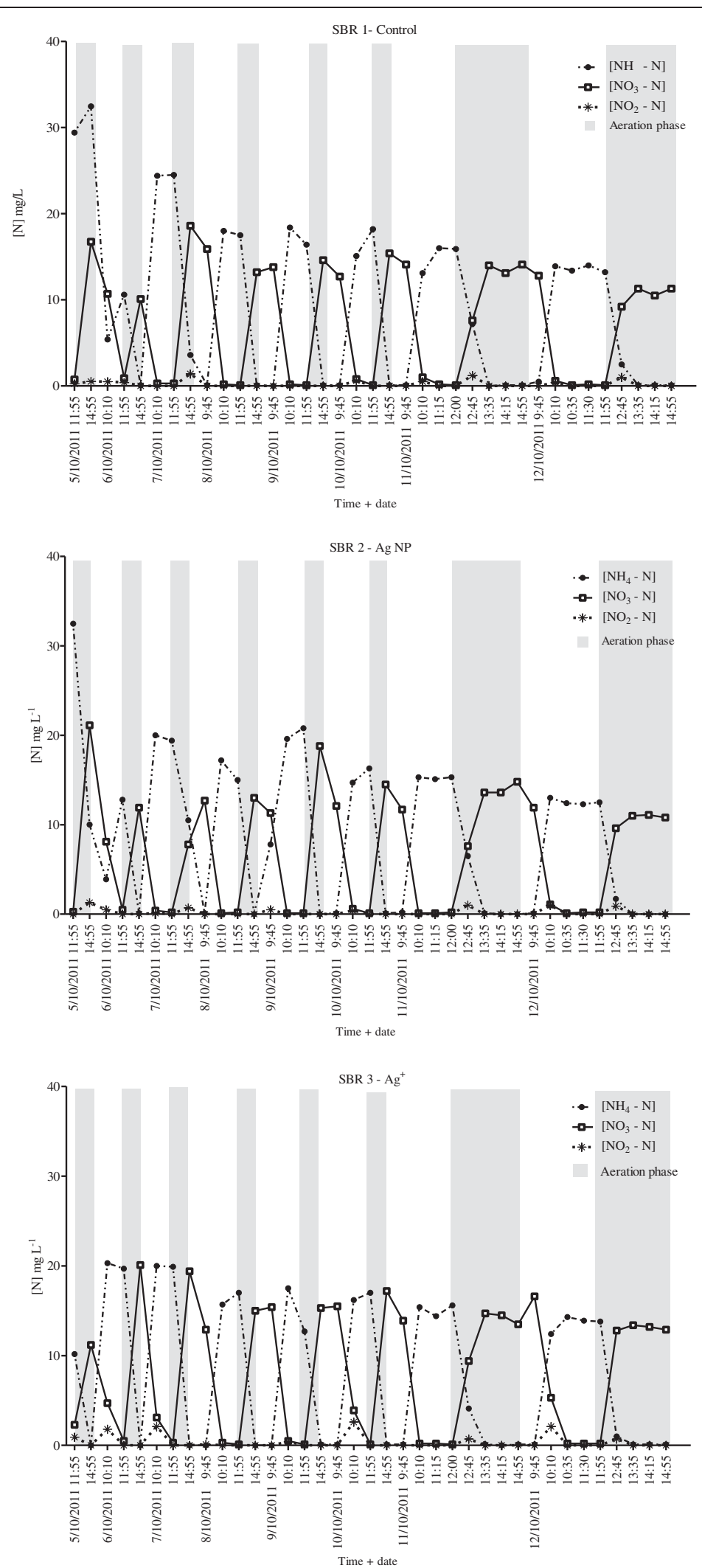

Figure $\mathbf{5} \mathbf{N H}_{4}^{+}$and $\mathbf{N O}_{\mathbf{x}}$ profiles of each SBR. Results are shown from day 2 to day 9 (after spiking). Sample collection commenced on day 1; the second day of SBR operation (results not shown). Samples were collected daily during one cycle (4 cycles in $24 \mathrm{~h}$ ). 


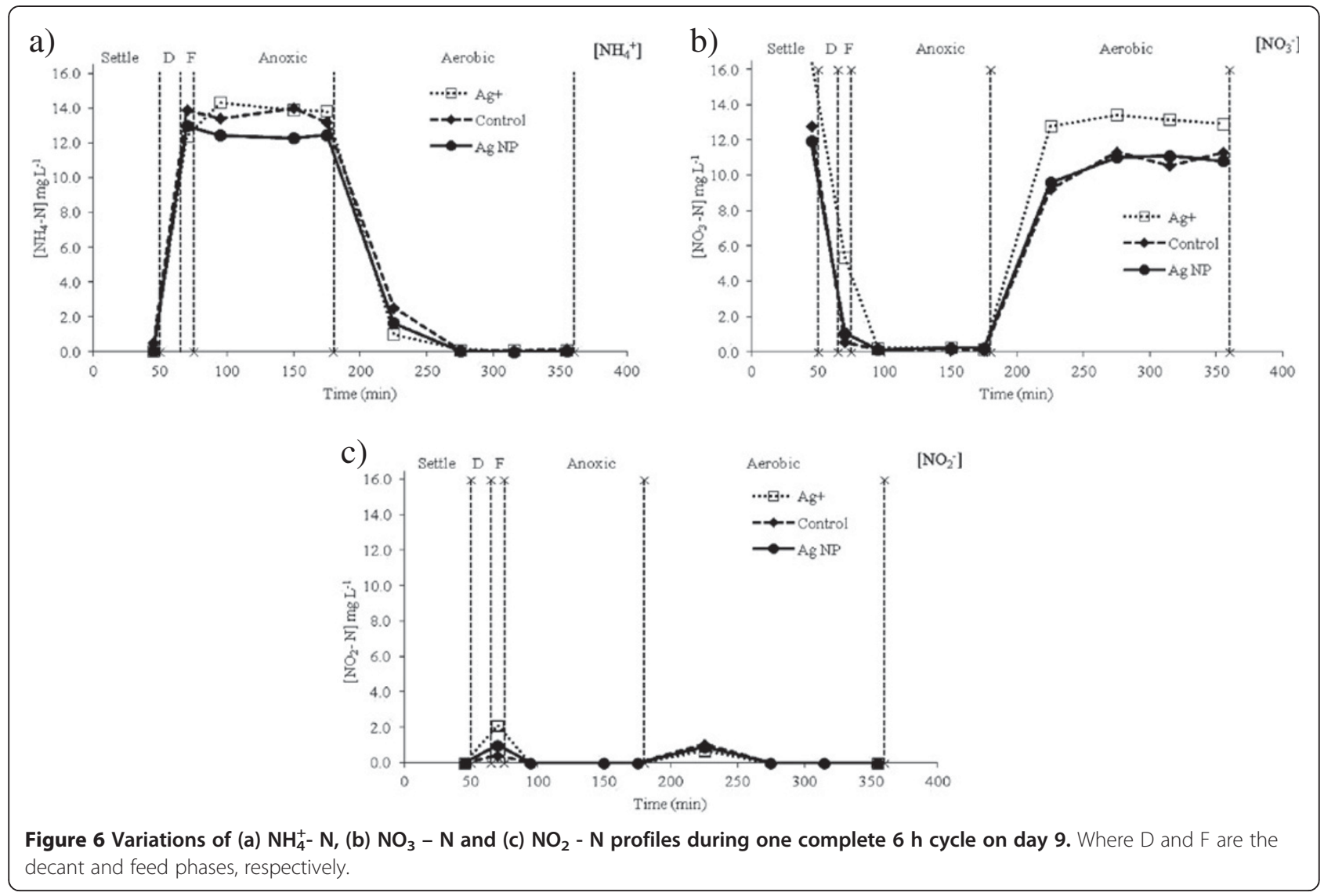

$[9,14,15,18]$. As the sludge matrix is likely to have a major influence on the fate of AgNPs in WWTP, the results from the current experiment are most comparable to those experiments that have used WWTP sludge and activated sludge $[9,15]$; not synthetic wastewater. In a 15 d simulated SBR experiment [9], $\mathrm{NH}_{4}^{+}$removal efficiency was not affected by AgNPs in wastewater $(0.5 \mathrm{mg} \mathrm{Ag}$ $\left.\mathrm{L}^{-1}\right)$, whereas in a short term $(12 \mathrm{~h})$ batch test using a synthetic feed solution [15], a 7\% decrease in nitrification rate at $1 \mathrm{mg} \mathrm{AgNP} \mathrm{L}{ }^{-1}$ was recorded. This inhibition may be due to the relatively high DO concentrations $\left(\sim 7.2-\mathrm{mg} \mathrm{L}^{-1}\right)$ compared to the more realistic concentrations used in our experiment $\left(1.5-2.5 \mathrm{mg} \mathrm{L}^{-1}\right)$.

In the current experiment, the complex sludge matrix may have decreased AgNP toxicity for a number of

Table 3 Nitrification rate for each SBR on days 8 and 9 of the experiment

\begin{tabular}{lcc}
\hline SBR & $\begin{array}{c}\text { Day } \mathbf{8} \\
\mathbf{~ g ~ L ~ L}^{-1} \mathbf{h}\end{array}$ & $\begin{array}{c}\text { Day } \mathbf{9} \\
\mathbf{m g ~ L}^{-1} \cdot \mathbf{h}\end{array}$ \\
\hline Control & 2.4 & 1.8 \\
$\mathrm{Ag}^{+}$ & 1.5 & $1.3(1.2)$ \\
AgNP & $2.6(2.2)$ & 1.6 \\
\hline
\end{tabular}

Rates calculated from the on-line $\mathrm{NH} 4$ probe are shown in parentheses. All rates have been normalised for TSS content. reasons, with two primary factors being the presence of organic matter and the high ionic strength. Organic matter complexes $\mathrm{Ag}^{+}$[31,32], which has been linked to AgNP toxicity, whereas high salt concentrations cause NP aggregation which is known to decrease nanoparticle toxicity [33]. In addition, $\mathrm{Ag}^{+}$anion binding may produce very

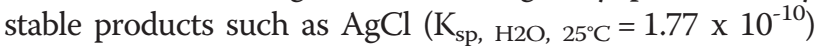

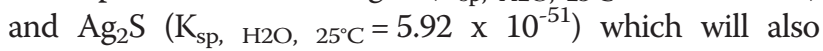
decrease $\mathrm{Ag}^{+}$bioavailability and hence toxicity.

\section{Effect of silver nanoparticles on methane production}

The cumulative production of biogas (methane) during anaerobic digestion of the $\mathrm{AgNP}$ and $\mathrm{Ag}^{+}$dosed sludges is shown in Figure 7. Based on the calculated anaerobic biodegradability parameters, AgNPs did not have an impact on sludge digestion (Table 4). There was no difference between the methane production of AgNP, $\mathrm{Ag}^{+}$ and control sludges at $\mathrm{Ag}$ concentrations of 184, 77 and $6.3 \mathrm{mg} \mathrm{Ag} \mathrm{kg}^{-1}$. The results concur with previous studies that found methanogenesis was not affected by AgNPs at concentrations $<18.9 \mathrm{mg} \mathrm{Ag} \mathrm{L}^{-1}[18]$ and $40 \mathrm{mg} \mathrm{Ag} \mathrm{L}^{-1}$ [19]. Similarly, for bulk Ag, the rate and extent of methanogenesis in mixed cultures was not affected by either $\mathrm{AgNO}_{3}$ or $\mathrm{Ag}_{2} \mathrm{~S}$ at concentrations of $100 \mathrm{mg} \mathrm{Ag} \mathrm{L}-1$ [34]. To the best of our knowledge, the results are the 


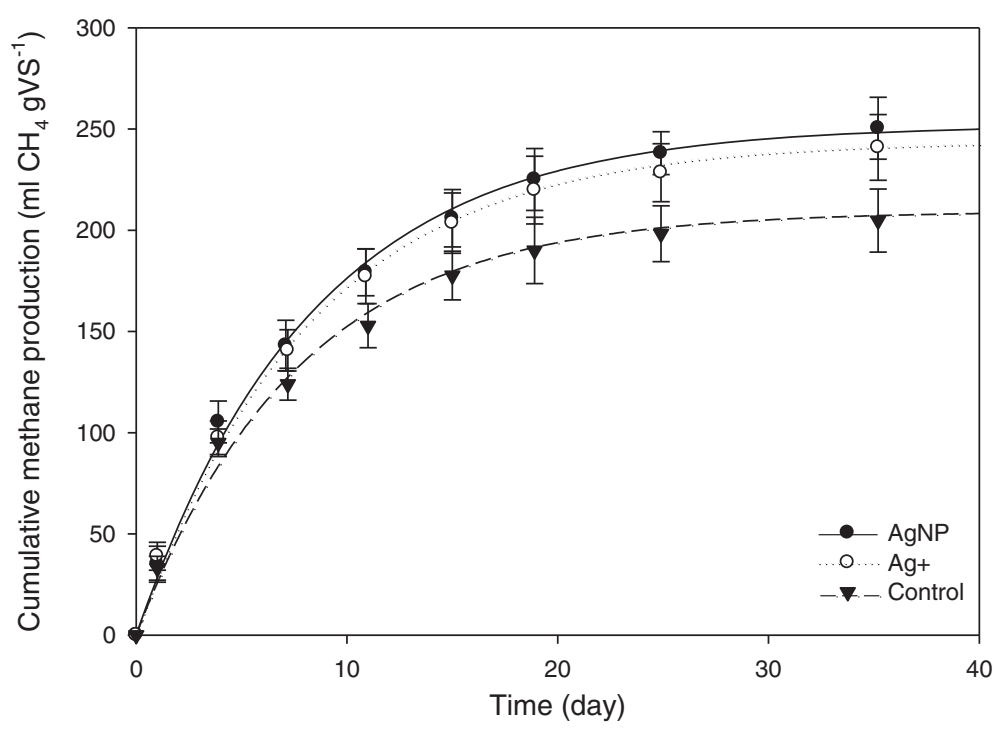

Figure 7 Cumulative methane produced during the $\mathbf{3 8} \mathbf{d}$ anaerobic digestion. All values are blank corrected and the error bars show $95 \%$ confidence intervals calculated from triplicate measurements.

first to demonstrate that transformed AgNPs in sludges (present mainly as $\mathrm{Ag}$ bonded to $\mathrm{S}$ groups) (Table 1), as opposed to 'pure' AgNPs, have no effect (at $184 \mathrm{mg} \mathrm{Ag} \mathrm{kg}^{-1}$ ) on methanogenic processes which are essential for sludge degradability in WWTPs.

\section{Effect of silver nanoparticles on niche microbial communities}

Following mixed liquor digestion in the three SBRs and anaerobic assays, the diversity of bacterial populations was determined and compared to that of influent wastewater, activity sludge mixed liquor (aerobic inoculum) and anaerobic inoculum. The results from a PCA of the individual data sets shows that all samples could be grouped based on their source (Figure 8). In each case, there was a slight shift from control/ $\mathrm{Ag}^{+}$to AgNP.

One dimension could account for $70 \%$ of overall variation. Aerobic samples were heavily dominated by a major dominant $\gamma$-Proteobacteria $19 \%, 22 \%$ and $21 \%$ for the control, AgNP and $\mathrm{Ag}^{+}$aerobic samples, respectively (Figure 8) This is surprising as nitrifiers and phosphate accumulating organisms (PAOs) in activated sludge are usually $\beta$-Proteobacteria with only a small percentage

Table 4 Anaerobic biodegradability of each sludge as indicated by degradation extent $\left(f_{d}\right)$, apparent first order hydrolysis rate coefficient $\left(k_{h y d}\right)$ and the estimated methane potential $\left(B_{0}\right)$

\begin{tabular}{lccc}
\hline Treatment & $\mathbf{k}_{\text {hyd }}\left(\mathbf{d}^{-\mathbf{1}}\right)$ & $\boldsymbol{f}_{\mathbf{d}}$ & $\boldsymbol{B}_{\boldsymbol{o}}(\mathbf{m L} / \mathbf{g V S})$ \\
\hline Control & $0.13 \pm 0.020$ & $0.31 \pm 0.016$ & $195 \pm 1$ \\
$\mathrm{Ag}+$ & $0.12 \pm 0.014$ & $0.36 \pm 0.014$ & $228 \pm 9$ \\
AgNP & $0.12 \pm 0.014$ & $0.36 \pm 0.014$ & $238 \pm 9$ \\
\hline
\end{tabular}

from the gamma subclass. Removal of organic $\mathrm{N}$ is a two-step process where ammonia is initially oxidised to nitrite by ammonia oxidising bacteria $(\mathrm{AOB})$ and then further oxidised to nitrate by nitrite oxidising bacteria (NOB). All AOB belong to two genera each in the $\beta$-Proteobacteria and $\gamma$-Proteobacteria phylum, whereas NOB belong to five genera in various classes of the Proteobacteria. The primary habitats of $\gamma$-Proteobacteria are marine environments whereas $\beta$-Proteobacteria dominate in freshwater systems. The inoculum plant was in a coastal environment (more saline), which could account for this increased dominance.

Ammonia oxidising bacteria are generally more sensitive to toxicants than NOB $[16,35]$. There was a very minor response to the AgNP treatment, driven mainly by slight shifts in niche populations. Subdominant microbial structure in the $\mathrm{Ag}^{+}$treated sludges was not significantly different to that of the control. What was more surprising was that there was almost no shift in population between the inoculum and $\mathrm{Ag}^{+}$and control. This is surprising as the feed is different, the mode of operation is different (continuous in parent vs sequenced in SBR), and at least 1 nominal sludge age occurred through the study. The pyrosequencing data confirms the nitrification results, in that AgNPs at a concentration of

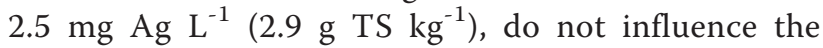
broad microbial population.

Anaerobic samples indicated that control and $\mathrm{Ag}^{+}$were very similar, but with a large shift from inoculum to batch, and a small shift from control/ $\mathrm{Ag}^{+}$to AgNP (Figure 9). This was confirmed through additional PCA analysis on the anaerobic samples only (top 500 OTUs, Hellinger adjusted). This indicated a large shift from inoculum to end 


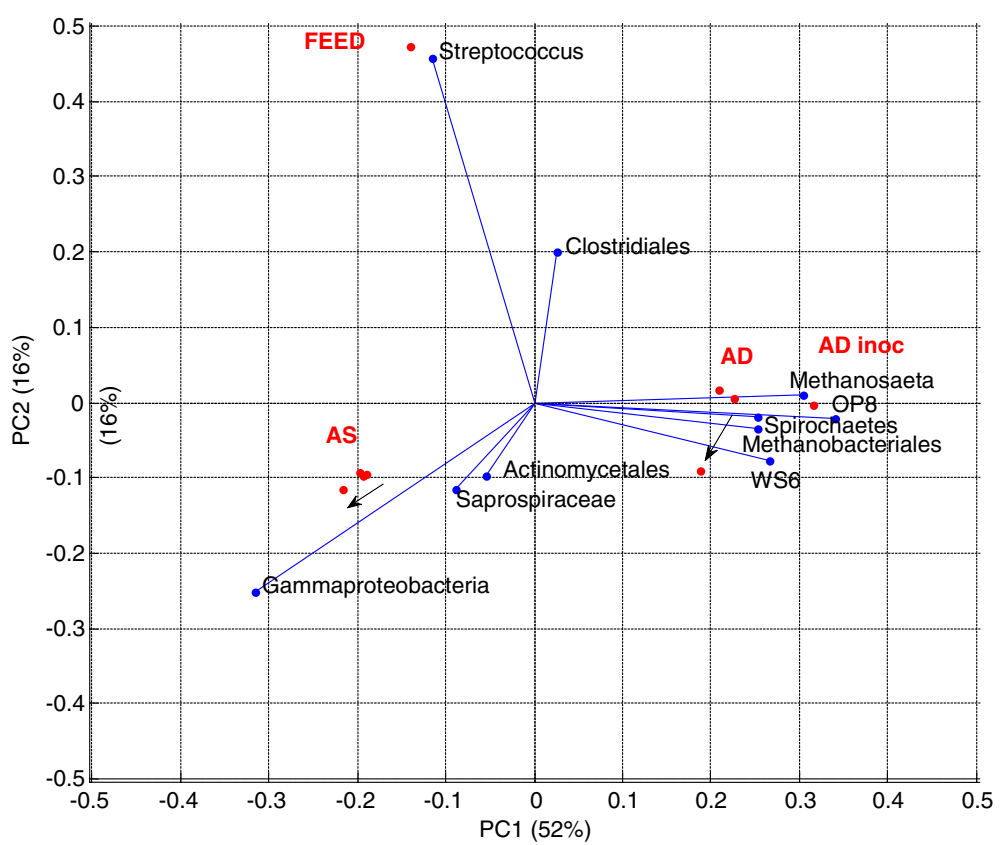

Figure 8 Overall bi-plot of PCA data showing top 10 OTUs. All OTUs were used for analysis. The key clusters of Activated sludge - AS (inoculum $\mathrm{Ag}^{+}$, and control overlap), Feed, and Anaerobic Digestion (AD) are shown. Arrows show shift from control and $\mathrm{Ag}^{+}$to $\mathrm{AgNP}$ communities. Note that AD Inoculum is right-shifted on PC1 compared to the control and $\mathrm{Ag}^{+}$samples.

BMP, with a dominant WS6 OTU being largely replaced by OP8 (both candidate divisions), and a number of other major OTUs. Silver NPs seemed to cause a subtle shift from Spirochaetes to other organisms. Archaea seemed not at all influenced by batch operation, or $\mathrm{Ag}^{+} / \mathrm{AgNP}$ treatment. Our data therefore support those in previous studies [19] indicating no impact of AgNPs on Archaea compared to controls (at $20 \mathrm{mg} \mathrm{AgNP} \mathrm{L}^{-1}$ ).
What is surprising is the dominance in all anaerobic samples by uncultured division OTUs (Figure 9). The inoculum contained phyla from the uncultured candidate division WS6 (18\%), whereas microbial population in anaerobic samples collected after digestion appeared to be dominated $(10-17 \%)$ by organisms from another candidate division (OP8). The cause of this shift in diversity is unclear. The WS6 phyla was first identified in a

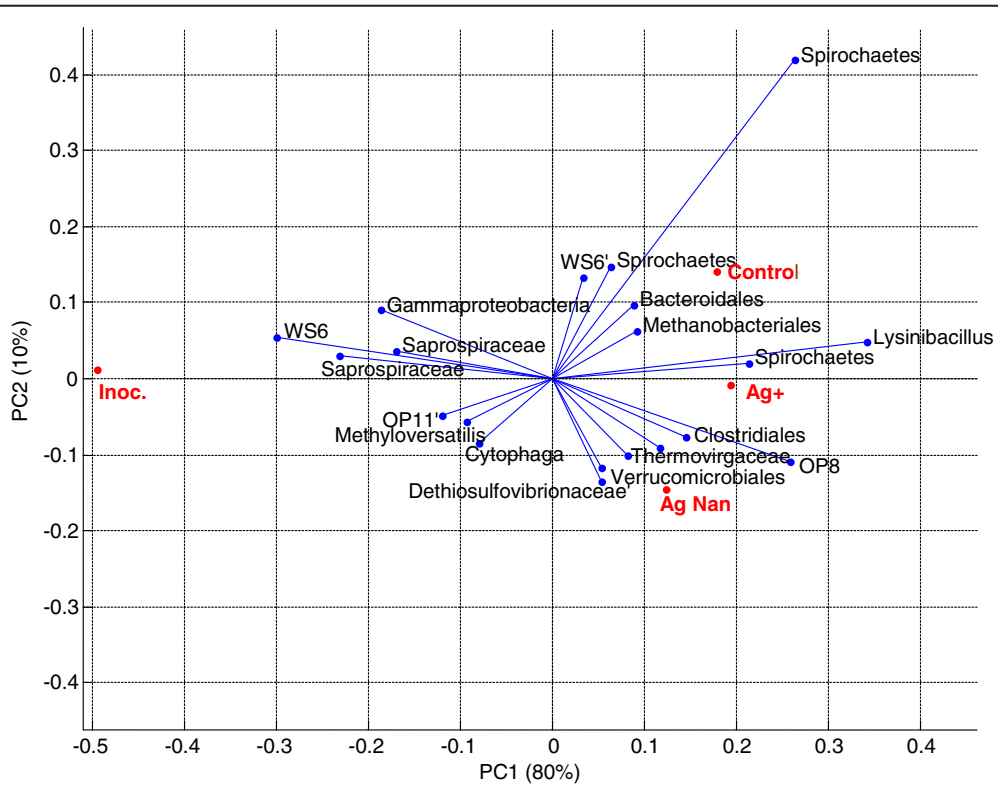

Figure 9 PCA analysis of anaerobic pyrotag results only. 
contaminated aquifer and has since been identified in other environments (e.g. anoxic pond sediment [36], sulfur-rich spring sediments [37], eutrophic estuaries [38], hydrothermal vents [39]) but not in sludges or wastewater. Organisms from the OP8 division have been identified in mangrove sediments [40] and an anaerobic sludge digester, where $1 \%$ of the operational taxonomic units (OTUs) were represented by organisms from this division [41]. Broadly speaking, environmental bacterial community structure is regulated by local conditions. Hence, in the BMP test, factors including salinity and nutrient conditions [42] may have differed to that in the tank where inoculum was collected causing the population change.

Sensitive methanogenic microbes (Methanosaetaceae) accounted for $\sim 11 \%$ of the variation in all anaerobic samples, including the inoculum, and was not impacted by the presence of AgNPs (Figure 9). This organism is most sensitive to possible surface active agents [21]. It is highly important that the bacterial population changed so strongly between inoculum and the end of the batch, while the archaeal population seemed untouched. This means that the mode of operation has a strong impact on acidogenic microbial populations but not methanogenic ones. It will be important to further evaluate the role of organisms in candidate divisions, as almost nothing is known of these microbes.

Whilst previous studies have investigated the effects of pure AgNPs on wastewater microbial populations, this is the first time that the influence of transformed AgNPs (primarily as Ag-S species) has been investigated. Moreover, to the best of our knowledge, this is also the first time that transformed AgNPs have been shown to affect niche populations. The results cannot conclusively be attributed to a nano- effect due to the higher spike concentration of $\mathrm{Ag}$ in the AgNP treated sludge compared to the $\mathrm{Ag}^{+}$sludge. Yet, XAS analysis of the anaerobic sludges did show a greater percentage of nano sized $\mathrm{Ag}_{2} \mathrm{~S}$ in the $\mathrm{AgNP}$ treated sludge compared to $\mathrm{Ag}^{+}$ dosed sludge (78\% cf. 53\%, respectively) and a lower percentage of bulk $\mathrm{Ag}_{2} \mathrm{~S}$ (13\% cf. $30 \%$, respectively). This supports our hypothesis that the observed population changes are attributable to a nano-effect, although further research is required to confirm this hypothesis. Nevertheless, the results still demonstrate that even after their transformation to much less toxic Ag-S species, AgNPs have the potential to impact niche microbial communities but are not likely to impact overall WWTP microbial processes (e.g. nitrification and methanogenesis).

\section{Conclusions}

In our experiments, $>99 \%$ of PVP-coated AgNPs were removed from wastewater when subjected to activated sludge digestion. During the SBR experiment and subsequent anaerobic digestion stage, nitrogen removal and methane production (respectively) were not affected by transformed AgNPs.

Pyrosequencing analysis of microbial communities showed that AgNPs and $\mathrm{Ag}^{+}$did not affect the dominant populations of nitrifiers and methanogenic organisms in aerobic and anaerobic generated sludges, respectively. However, in both sludges a subtle shift in niche populations was observed. In the case of aerobic sludge samples, the shift was extremely minor, whilst for anaerobically digested samples there was a much larger shift. Additional studies are required to confirm if this change in population is exclusively a nano- effect.

Two conclusions were drawn from the XAS analysis of sludge: (i) AgNPs were sulfidised during SBR operation followed by near complete sulfidation during anaerobic digestion; and (ii) AgNP dosed anaerobic sludge contained a higher fraction on nano sized $\mathrm{Ag}_{2} \mathrm{~S}$ species compared to $\mathrm{Ag}^{+}$dosed sludge. The production of stable Ag-S species may have limited the toxicity of AgNPs towards nitrifiers and methanogenic bacteria as $\mathrm{Ag}^{+}$is believed to be the main toxicity mechanism of AgNPs.

Based on our results, PVP-coated AgNPs will not affect nitrification and methanogenesis during WWT, even in the future with the increasing use of AgNPs. Further investigations are required to confirm whether sub-dominant microbial sludge populations are at risk from AgNP exposure, as this may have long term consequences for the successful operation of WWTPs.

\section{Methods}

\section{Preparation and characterisation of nanoparticle stock} solutions

Polyvinylpyrrolidone (PVP) coated (0.1\%) Ag NP powders were purchased from Nanostructured \& Amorphous Materials, Inc. (Houston, TX) (10 nm nominal particle size diameter). PVP coated NPs were chosen as they are a very common AgNP capping agent. Thus, their use is realistic of the AgNPs that would be released into wastewater streams. Stock suspensions of AgNPs were prepared by adding the NP powder $(0.1 \mathrm{~g})$ to ultrapure deionised water $(50 \mathrm{~mL}, 18.2 \Omega)$ and sonicating $(1800 \mathrm{~W}, 3 \mathrm{~min})$ in an ice bath. The AgNP suspension was then centrifuged (2200 g, $15 \mathrm{~min})$ producing a final stock suspension with an average $\mathrm{Ag}$ concentration of $35.7 \mathrm{mg} \mathrm{Ag} \mathrm{L}^{-1}$ ( $\mathrm{SD}=5.6 \mathrm{mg} \mathrm{Ag} \mathrm{L}^{-1}, \mathrm{n}=11$ ), 8\% of which was dissolved ionic $\mathrm{Ag}^{+}$[43]. The AgNP stock suspensions were prepared daily (30 - 60 min before spiking). Total Ag concentrations of the NP spiking solutions were determined by an open-vessel acid digestion $\left(\mathrm{HNO}_{3}, 70 \%\right)$ method as described previously [43].

The AgNP suspensions prepared with this method have been extensively characterized previously using dynamic light scattering (DLS, Malvern Zetasizer), 
transmission electron microscopy (TEM, Phillips CM200 at $120 \mathrm{keV}$ ) and X-ray diffraction analysis [44]. The particle size distribution has also been investigated using disk centrifuge analysis (CPS Instruments disc centrifuge 24000 UHR). In summary, the average particle diameter was between $40 \mathrm{~nm}$ with $<8 \%$ of $\mathrm{Ag}$ existing as dissolved $\mathrm{Ag}^{+}$(Additional file 1: Table SI.1 for complete NP characterisation) [44]. Previous work [44] (using the same method and batch of nanoparticles) has showed that the volumetric diameters of the AgNPs observed using TEM corresponded with the crystallite size determined from X-Ray diffraction analysis, the hydrodynamic diameter $\left(\mathrm{d}_{\mathrm{h}}\right)$ observed using DLS and the Stokes diameter as found using disk centrifugation.

\section{Set-up and operation of sequencing batch reactors}

Three individual SBRs (control, $\mathrm{Ag}^{+}$and AgNPs) with a working volume of $5 \mathrm{~L}$ and an initial TSS of $6.0 \mathrm{~g} \mathrm{~L}^{-1}$ were prepared with $0.9 \mathrm{~L}$ of activity sludge mixed liquor $\left(\mathrm{TS}=35.3 \mathrm{~g} \mathrm{~L}^{-1}\right.$ ) and $4.1 \mathrm{~L}$ of influent wastewater. Activated biological nutrient removal (BNR) sludge was collected from an activated sludge wastewater treatment plant (Luggage Point), and influent wastewater was collected from a local domestic wastewater pumping station (Indooroopilly), both located in Brisbane, Queensland, Australia.

Each SBR was operated with four $6 \mathrm{~h}$ cycles per day with a hydraulic retention time (HRT) of $15 \mathrm{~h}$. Each cycle consisted of a $3 \mathrm{~h}$ aerated aerobic phase, followed by 50 min settling, 15 min decanting, 10 min feeding and 105 min anoxic [low dissolved oxygen (DO)] phases. Feeding, decanting and sampling ports were located at different positions on the reactors. During the $3 \mathrm{~h}$ aerobic stage, DO levels were maintained between 1.5 $2.5 \mathrm{mg} \mathrm{L}^{-1}$ by intermittent aeration, controlled with an online DO detector. Following the settling phase, $3 \mathrm{~L}$ of supernatant was decanted and $3 \mathrm{~L}$ of cold influent wastewater $\left(20^{\circ} \mathrm{C}\right)$ was pumped into each SBR. The reactors were continuously stirred with a magnetic stirrer except during settling and decant phases.

Silver (as NPs or $\mathrm{AgNO}_{3}$ ) was added once every $24 \mathrm{~h}$ at the beginning of a feed cycle and for the remaining three feed cycles in that 24 hours no $\mathrm{Ag}$ was added. Prior to spiking, trace amounts of Ag were recorded in the mixed liquor of each SBR (day 0), (36, 26 and $24 \mu \mathrm{g} \mathrm{Ag} \mathrm{L}^{-1}$ for the control, $\mathrm{Ag} \mathrm{NP}$ and $\mathrm{Ag}^{+}$dosed SBRs, respectively).

Following the 10 day aerobic digestion, sludge was allowed to settle for $2 \mathrm{~h}$ and the supernatant decanted. The remaining sludge in each SBR was centrifuged ( $2 \mathrm{~min}, 3250 \mathrm{~g}$ ), to increase the TS concentrations (Table 5), and approximately half was used in the subsequent anaerobic digestion experiment.
Table 5 Average characteristics of each sequence batch reactor

\begin{tabular}{lccc}
\hline Characteristic & Control SBR & Ag NP SBR & $\mathbf{A g}^{+} \mathbf{S B R}$ \\
\hline Average $\mathrm{pH}$ & $6.71(0.23)$ & $6.67(0.07)$ & $6.62(0.09)$ \\
Final TSS $\left(\mathrm{g} \mathrm{L}^{-1}\right)$ & 4.4 & 4.5 & 6.3 \\
Final VSS $\left(\mathrm{g} \mathrm{L}^{-1}\right)$ & 4.0 & 4.3 & 5.5 \\
$\begin{array}{l}\text { TS after centrifugation of SBR } \\
\text { sludge }\left(\mathrm{g} \mathrm{kg}^{-1}\right)\end{array}$ & 72.8 & 60.5 & 65.4 \\
$\begin{array}{l}\text { Sludge }[\mathrm{Ag}] \text { before spiking } \\
\left(\mathrm{mg} \mathrm{Ag} \mathrm{L}^{-1}\right)\end{array}$ & 0.04 & 0.03 & 0.02 \\
Total Ag added $(\mathrm{mg})$ & 0.00 & 12.73 & 6.14 \\
\hline
\end{tabular}

Mixed liquor suspended and volatile solids (MLSS and MLVSS, respectively) were analysed every $2 \mathrm{~d}$ according to APHA Standard Methods (1992). The chemical characteristics and Ag spiking concentrations of each SBR are given in Table 5.

\section{Transmission electron microscopy analysis of silver nanoparticles in sludge}

Freeze dried sludge was collected at the conclusion of the $10 \mathrm{~d}$ SBR process to determine whether physical or chemical transformation of AgNPs had occurred in the AgNP dosed SBR. STEM analysis in HAADF mode was used to investigate the morphology of AgNPs in the sludge, whereas EDX together with TEM was used for elemental analysis. Samples of aerobic sludge were collected at the end of the SBR experiment. Samples were freeze-dried and analysed using a JEOL 2100 TEM operating at $200 \mathrm{kV}$. Freeze dried samples were ground in methanol using a mortar and pestle and a single drop pipetted onto a 200-mesh copper $(\mathrm{Cu})$ TEM grid with lacey carbon support film and allowed to evaporate at room temperature.

The elemental composition of "bright" NPs/aggregates was investigated using an EDX spectrometer. The TEM was used in scanning mode (STEM) with a high-angle annular dark-field (HAADF) detector. The high angle detector collects transmitted electrons that are scattered (primarily incoherently) to high angles, whilst excluding Bragg (coherent) scattering. The detector provides an image where the contrast is dependent on the approximate square of the atomic number $(Z)$. Accordingly, bright spots in the image correspond to high $Z$ elements; making the detection of $\mathrm{Ag}$ containing particles in the complex sludge matrix more straight forward than that in a bright-field image.

\section{Solid phase speciation of silver in sludge using synchrotron radiation}

Solid phase speciation of $\mathrm{Ag}$ in aerobic and anaerobic sludges was further examined using X-ray absorption 
spectroscopy (XAS); specifically X-ray absorption near edge structure (XANES) and extended X-ray absorption fine structure (EXAFS) analysis.

Silver K-edge X-ray absorption spectra were recorded on the XAS beamline at the Australian Synchrotron (AS), Melbourne, Australia. The $3 \mathrm{GeV}$ electron beam was maintained at a current of $200 \mathrm{~mA}$ in top-up during the sample analysis. The X-ray beam was tuned with a Si (311) monochromator in the energy ranges of 25312-25492 eV for pre-edge (10 eV steps), 25492-25562 eV XANES region (0.5 eV steps) and then $0.035 \AA^{-1}$ steps in k-space for EXAFS. A metallic $\mathrm{Ag}$ foil, recorded in transmission mode downstream of the sample, was used as an internal standard to calibrate the energy scale to the first peak of the first derivative of the $\mathrm{Ag}$ edge $(25515 \mathrm{eV})$. Spectra of the samples were recorded in fluorescence mode on a 100-pixel Ge detector array at $90^{\circ}$ to the incident beam (Canberra/UniSys).

Freeze-dried sludges (aerobic and anaerobic) were finely ground to a homogenous powder and compressed into pellets with a hand press. Samples that had a high $\mathrm{Ag}$ concentration were diluted with cellulose material (Sigma-Aldrich). All samples were cooled to $\sim 10 \mathrm{~K}$ in a Cryo Industries (Manchester, New Hampshire, USA) cryostat. One to eight scans per sample were collected for XANES spectra and 14 scans per sample were collected for EXAFS spectra. Reference materials measured at the XAS beamline included PVP-coated AgNPs (Nanoamor), $\mathrm{AgNO}_{3}, \mathrm{Ag}_{2} \mathrm{~S}, \mathrm{Ag}_{2} \mathrm{O}, \mathrm{AgCl}, \mathrm{Ag}_{2} \mathrm{CO}_{3}$, and $\mathrm{Ag}_{2} \mathrm{SO}_{4}$ (all purchased from Sigma Aldrich). Additional standards were prepared the day of analysis and stored in the dark until use; $\mathrm{Ag}_{2} \mathrm{PO}_{4}, \mathrm{Ag}$-goethite, Ag-kaolinite, Ag-humic acid complex, Ag-fulvic acid complex, Ag thiosulfate (STS), Ag-acetate, Ag-glutathione (Ag-GSH) and $\mathrm{Ag}_{2} \mathrm{~S}$ NPs. (See Supporting Information for synthesis and preparation of all Ag standards).

\section{Solid phase speciation of silver nanoparticles in wastewater using synchrotron radiation}

A short term exposure experiment $(3 \mathrm{~h})$ was undertaken to examine the potential rapid transformation/reactions of AgNPs in wastewater (in the absence of activated sludge) using synchrotron based XAS. PVP coated AgNPs were spiked into wastewater $(500 \mathrm{~mL})$ to a final concentration of $5.4 \mathrm{mg} \mathrm{Ag} \mathrm{L}^{-1}$. The wastewater was the same as that which was used in the SBR study. The AgNP-wastewater suspension was stirred continuously for $210 \mathrm{~min}$ and the DO concentration was measured with an online DO detector $\left(7.4 \mathrm{mg} \mathrm{O}_{2} \mathrm{~L}^{-1}\right.$ to $7.1 \mathrm{mg}$ $\left.\mathrm{O}_{2} \mathrm{~L}^{-1}\right)$. Approximately one $\mathrm{mL}$ of the suspension was collected at $\mathrm{t}=4,10,24,45,60,94$ and $210 \mathrm{~min}$ after the addition of AgNPs. Each sample was collected using a two $\mathrm{mL}$ glass syringe and injected directly into a leucite cuvette, secured with Kapton tape, immediately flash frozen in liquid $\mathrm{N}_{2}$ and stored in dry ice until XAS analysis.

\section{XAS data analysis}

The chemical speciation of each sample was determined by fitting a linear combination of model compounds to each XANES spectrum (Additional file 1: Figure SI.3). The number of components in the sample XANES spectra was determined using principal component analysis (PCA) of all sample spectra, followed by target transformation to identify the most likely components of the spectra from a model compound library. The number of components to fit were chosen from the eigenvalues from the PCA and visual inspection of the plot of eigenvectors.

Linear combinations of the six spectra were fitted to each sample spectrum with the best fit to the experimental spectrum achieved by least squares refinement of the model compounds to the experimental spectrum. The best fits were improved by the removal of small components $(<1 \%)$ and the adequacy judged by the size of the residual and visual inspection to ensure that all features were accounted for.

Calibration, averaging and background subtraction of all spectra and principle component, target and multiple linear regression analyses of XANES spectra were performed using EXAFSPAK software package (G.N. George, SSRL).

\section{Investigation of nitrification inhibition and silver partioning during aerobic digestion}

For nitrification analysis, homogenous mixed liquor samples were collected daily at the end of feed, anoxic, aerobic and settling phases during one $6 \mathrm{~h}$ cycle for the first $7 \mathrm{~d}$ of SBR operation. On days 9 and 10, more frequent sampling was conducted during the aerobic and anaerobic phases. Samples were filtered $(<0.22 \mu \mathrm{m})$ and stored at $4{ }^{\circ} \mathrm{C}$ until analysis.

The choice of Ag spiking rate was a compromise between realistic environmental exposure concentrations [11], previous partitioning studies of Ag NP in wastewater $[8,18]$ and instrumental detection limits. Taking these factors into account, the aim was to produce sludges with a final concentration of $\sim 100 \mathrm{mg} \mathrm{Ag} \mathrm{kg}{ }^{-1} \mathrm{TS}$ for the $\mathrm{Ag}^{+}$and AgNP treatments.

The SBRs were operated for $24 \mathrm{~h}$ before spiking to allow for equilibration of the mixed liquor. Reactors 2 and 3 received the $\mathrm{AgNP}$ and $\mathrm{Ag}^{+}$(as silver nitrate $\left(\mathrm{AgNO}_{3}\right)$ ) treatments, respectively. Reactor 1 was assigned the control SBR and received ultrapure deionised water (Millipore) at each spiking event in order to maintain a consistent volume for all three reactors. Treatments were added once daily, for $8 \mathrm{~d}$, 
to each SBR at the beginning of the aeration phase by pipetting the spiking solution directly into the reactor. Each reactor received a total of $330 \mathrm{~mL}$ of the assigned spiking solution (nominal concentration for $\mathrm{AgNO}_{3}$ and AgNP suspensions $=20 \mathrm{mg} \mathrm{Ag} \mathrm{L}{ }^{-1}$ ). The Ag concentration of the ultrapure deionised water used in the control SBR was below the limit of detection for ICP-MS analysis $\left(<0.05 \mu \mathrm{g} \mathrm{L}^{-1}\right)$. Reactors were operated for a total of $10 \mathrm{~d}$.

For silver analysis, mixed liquor $(10 \mathrm{~mL})$ and effluent $(35 \mathrm{~mL})$ samples were collected once daily from each SBR; 3 and $5.5 \mathrm{~h}$ after spiking, respectively. Samples were acidified and stored at $4^{\circ} \mathrm{C}$ before subsequent digestion and analysis for total Ag by ICP-MS.

\section{Anaerobic digestion and biomethane potential test}

The effect of AgNPs on anaerobic digestion was assessed using a biomethane potential (BMP) test as previously described [45]. Anaerobic biomethane potential tests (BMP) were carried out for AgNPs and $\mathrm{Ag}^{+}$using sludge collected from each SBR at the conclusion of that experiment (all assays in triplicate). The inoculum (activity sludge) had a broad trophic microbial composition to ensure the substrate would not be limited. Blank assays (in triplicate) were used to determine the background methane production from the inoculum.

Aerobically digested sludges from the SBRs (substrate) were diluted to $30 \mathrm{~g} \mathrm{~L}^{-1}$ (TSS) with ultrapure deionised water (Millipore). Substrate (40 g wet) and inoculum (60 g wet) (anaerobic digestate from a municipal WWTP, Brisbane, Queensland) were added to glass serum bottles (160 mL working volume), flushed with high purity $\mathrm{N}_{2}$ gas for $3 \mathrm{~min}\left(1 \mathrm{~L} \mathrm{~min}^{-1}\right)$, sealed with a butyl rubber stopper and aluminium crimp-cap and stored in a temperature controlled incubator $\left(36^{\circ} \mathrm{C}\right)$ for 38 d. Blanks $(n=3)$ contained inoculum $(60 \mathrm{~g})$ and ultrapure deionised water $(40 \mathrm{~mL})$ (Millipore). Each assay was performed in triplicate. Once daily methane production had ceased ( $38 \mathrm{~d}$ ) the batches were terminated, and analysis of the microbial community was conducted. Biogas volume was measured periodically (initially daily) and the quality $\left(\mathrm{CH}_{4}, \mathrm{CO}_{2}, \mathrm{H}_{2}\right)$ was analysed using gas chromatography, with a thermal conductivity detector (Perkin Elmer). Confidence intervals (95\%) were calculated from triplicate measurements and were $\leq 0.02 \mathrm{~g}$ COD $\mathrm{d}^{-1}$ for all samples. Excess $\mathrm{CH}_{4}$ was vented from each serum bottle periodically via syringe and measured by liquid displacement.

\section{Microbial community analysis: DNA extraction and $16 \mathrm{~s}$ Pyrotag Analysis}

To assess the potential impact of AgNPs on microbial diversity of sludge samples (aerobic and anaerobic), a massive parallel sequencing approach using pyrotag sequencing was used. Microbial diversity analysis was conducted on samples of activated sludge mixed liquor (Luggage Point WWTP), feed (Indooroopilly pumping station), sludge after aerobic digestion (control, $\mathrm{Ag}^{+}$and AgNP), anaerobic inoculum (Luggage Point WWTP) and anaerobic digestate (control, $\mathrm{Ag}^{+}$, and $\mathrm{Ag} \mathrm{NP}$ ).

Community genomic DNA from the anodic biofilms were extracted using FastDNA SPIN for Soil kit (MP Biomedicals, USA) and Fastprep beadbeating machine (Bio101, USA) according to the manufacturer's protocol. The 3 ' region of the $16 \mathrm{~S} / 18 \mathrm{~S}$ rRNA gene was targeted using universal primers $926 \mathrm{~F}$ (5'-AAACTYAAAKGAATT GACGG-3') and 1392R (5'-ACGGGCGGTGTGTRC-3'). Primer sequences were modified by the addition of Roche 454 adaptor 1 or 2 sequences and unique $5 \mathrm{bp}$ barcodes at the 5 ' end of the primer (sequences not shown) [46,47]. DNA concentration and purity was then determined by gel electrophoresis on 1\% agarose gel and spectrophotometrically using the NanoDrop ND-1000 (Thermo Fisher Scientific, USA). DNA was lyophilised using Savant SpeedVac Concentrator SVC100H (Thermo Fisher Scientific, USA) and submitted to the Australian Centre for Ecogenomics (ACE) for $16 \mathrm{~s}$ rRNA gene pyrotag sequencing on the Genome Sequencer FLX Titanium platform (Roche, USA). Pyrotag sequences were processed using Pyrotagger [48], and QIIME with correction via ACACIA. Operational taxonomic unit (OTU) tables were normalised, and a square root (Hellinger) transformation was applied to emphasise comparison of niche populations over dominants. A principal components analysis was then performed on the square root (Hellinger adjusted) normalised OTU table using Matlab (princomp command), and results visualised using biplot.

\section{Chemical analysis of silver spiking solutions, mixed liquor, effluent, and sludge}

Silver concentrations of the AgNP spiking solutions were determined using an open-vessel acid digestion $\left(\mathrm{HNO}_{3}, 70 \%\right)$ method as previously described [43].

Effluent and mixed liquor samples were analysed for Ag following microwave digestion in aqua regia according to the method used for wastewater previously [8]. Sludge samples (aerobic and anaerobic) were first dried at $40^{\circ} \mathrm{C}$ to constant weight, and then allowed to react with $\mathrm{H}_{2} \mathrm{O}_{2}$ before using the same aqua regia digestion method. Silver concentrations in all digested solutions were determined using ICP-MS (Agilent $7500 \mathrm{ce})$ and $\mathrm{He}_{(\mathrm{g})}$ as a collision gas $\left(4 \mathrm{~mL} \mathrm{~min}^{-1}\right)$ and monitoring $\mathrm{Ag}$ at $m / z 107$ and 109.

Filtered mixed liquor was analysed for $\mathrm{NH}_{4}^{+}, \mathrm{NO}_{2}^{-}$ and $\mathrm{NO}_{3}^{-}$using a Lachat QuikChem8000 Flow Injection Analyser. 


\section{Additional file}

Additional file 1: The following additional information data are available with the online version of this paper in Additional file 1. Methods for synthesis and preparation of synchrotron standards and sample preparation. Table SI.1. Characteristics of the silver nanoparticles (AgNPs) and AgNP stock suspensions. Figure SI.1. $\mathrm{NH}_{4}-\mathrm{N}$ profiles of the AgNP and $\mathrm{Ag}^{+}$dosed SBRs as measured by the $\mathrm{NH}_{4}^{+}$on-line detector. Table SI.2. The concentration of major and trace elements in the influent wastewater Figure SI.2. Difference XANES spectra of sludge and various Ag references used in LCF analysis. Figure SI.3. Ag K-Edge XANES spectra of all reference materials. Figure SI.4. Ag K-Edge XANES spectra of aerobic and anaerobic control sludges and wastewater from the influent experiment. Figure SI.5. Bulk silver (Ag) X-ray absorption near-edge spectroscopy (XANES) of sludge collected from the SBRs (a-c) and after the anaerobic batch test (d-f). Figure SI.6. Ag K-edge XANES spectra showing the considerable difference between aerobic sludge dosed with AgNP, and anaerobic sludge dosed with $\mathrm{Ag}^{+}$or AgNP. Figure SI.7. $\mathrm{k}^{3}$-weighted Ag K-edge EXAFS spectra of sludges and their respective phase-corrected Fourier transforms. Table SI.3. The higher residual values that resulted from the exclusion of Ag-acetate from the linear combination fitting analysis of XANES spectra of sludges.

\section{Abbreviations}

AgNPs: Silver nanoparticles; TEM: Transmission electron microscopy; EDX: Energy dispersive X-ray analysis; XAS: X-ray absorption spectroscopy; TSS: Total suspended solids; TS: Total solids; MNM: Manufactured nanomaterials; PVP: Polyvinylpyrrolidone; SBR: Sequencing batch reactor; DOC: Dissolved organic carbon; WWTP: Wastewater treatment plant; DLS: Dynamic light scattering; BNR: Biological nutrient removal; DO: Dissolved oxygen; HRT: Hydraulic retention time; OTU: Operational taxonomic units; SD: Standard deviation; STEM: Scanning transmission electron microscopy; HAADF: High angle annular dark field; PCA: Principal component analysis; LCF: Linear combination fitting; XANES: X-ray absorption near edge spectroscopy; EXAFS: Extended X-ray absorption fine structure; AS: Australian synchrotron; $\mathrm{Ag}^{+}$: Dissolved ionic silver; $\mathrm{Ag}^{0}$ : Elemental silver; $\mathrm{NH}_{4}^{+}$: Ammonium; $\mathrm{NO}_{3}^{-}$: Nitrate; $\mathrm{NO}_{2}^{-}$: Nitrite; $\mathrm{AgNO}_{3}$ : Silver nitrate; $\mathrm{Ag}$ GSH: Silver glutathione complex; $\mathrm{Ag}_{2} \mathrm{~S} N \mathrm{NP}$ : Silver sulfide nanoparticles; Agthio: Silver thiosulfate; Ag-HA: Silver - Humic acid; Ag-FA: Silver - Fulvic acid.

\section{Competing interests}

Authors declare that they have no competing interests.

\section{Authors' contributions}

CD: designed and conducted the experiments, interpreted results and wrote the manuscript. MJM: designed the experiments, interpreted results and participated in manuscript preparation. JK: designed the experiments, interpreted results and participated in manuscript preparation. DJB: assisted in experimental design, interpreted results and participated in manuscript preparation. $\mathrm{HHH}$ : conducted XAS experiments, participated in XAS data analysis, interpreted XAS results and participated in manuscript preparation. HG: Set-up the SBR experiments, conducted the anaerobic batch test and assisted in analysis of results. GC: Participated in experimental design, was involved in useful discussions and participated in manuscript preparation. All authors read and approved the final manuscript.

\section{Acknowledgements}

We thank Kenn (Yang) Lu for his assistance in DNA extraction and quality analysis, Fiona May at the Australian Centre for Ecogenomics (ACE) for performing the pyrotag sequencing, Dr Beatrice Keller-Lehmann for FIA of samples, Claire Wright (CSIRO) for ICP-MS analysis and Dr Graeme Auchterlonie at the Centre for Microscopy \& Microanalysis at The University of Queensland (CMM, UQ) for TEM/STEM/EDX analysis. This research was undertaken on the XAS beamline at the Australian Synchrotron, Victoria, Australia.

\section{Author details}

${ }^{1}$ School of Agriculture Food \& Wine, The University of Adelaide, PMB 1, Glen Osmond, SA 5064, Australia. ${ }^{2}$ CSIRO Land and Water, Environmental Biogeochemistry Program, Advanced Materials Transformational Capability
Platform-Nanosafety, Waite Campus, Waite Road, Urrbrae, SA 5064, Australia. ${ }^{3}$ Advanced Water Management Centre, The University of Queensland, St Lucia, 4072, Queensland, Australia. ${ }^{4}$ School of Chemistry and Physics, The University of Adelaide, Adelaide, SA 5005, Australia. ${ }^{5}$ Department of Chemistry, The University of Gothenburg, Kemivägen 10, 41296, Göteborg, Sweden.

Received: 3 January 2013 Accepted: 28 February 2013

Published: 4 March 2013

\section{References}

1. Batley GE, McLaughlin MJ: Fate of manufactured nanomaterials in the Australian environment. Final Report prepared for the Department of Environment, Heritage and the Arts. 2010:88. http://www.environment.gov. au/settlements/biotechnology/publications/pubs/manufacturednanomaterials.pdf.

2. PEN: The Project on Emerging Nanotechnologies. http://www.nanotechproject. org/inventories/.

3. Benn TM, Westerhoff P: Nanoparticle silver released into water from commercially available sock fabrics. Environ Sci Technol 2008, 42:4133-4139.

4. Geranio L, Heuberger M, Nowack B: The behavior of silver nanotextiles during washing. Environ Sci Technol 2009, 43:8113-8118.

5. Blaser SA, Scheringer M, MacLeod M, Hungerbuhler K: Estimation of cumulative aquatic exposure and risk due to silver: contribution of nanofunctionalized plastics and textiles. Sci Total Environ 2008, 390:396-409.

6. Kaegi R, Sinnet B, Zuleeg S, Hagendorfer H, Mueller E, Vonbank R, Boller M, Burkhardt M: Release of silver nanoparticles from outdoor facades. Environ Pollut 2010, 158:2900-2905.

7. Farkas J, Peter H, Christian P, Gallego Urrea JA, Hassellöv M, Tuoriniemi J, Gustafsson S, Olsson E, Hylland K, Thomas KV: Characterization of the effluent from a nanosilver producing washing machine. Environ Int 2011 37:1057-1062.

8. Kaegi R, Voegelin A, Sinnet B, Zuleeg S, Hagendorfer H, Burkhardt M, Siegrist $\mathrm{H}$ : Behavior of metallic silver nanoparticles in a pilot wastewater treatment plant. Environ Sci Technol 2011, 45:3902-3908.

9. Hou L, Li K, Ding Y, Li Y, Chen J, Wu X, Li X: Removal of silver nanoparticles in simulated wastewater treatment processes and its impact on COD and NH4 reduction. Chemosphere 2012, 87:248-252.

10. Wang $Y$, Westerhoff $P$, Hristovski KD: Fate and biological effects of silver, titanium dioxide, and C60 (fullerene) nanomaterials during simulated wastewater treatment processes. J Hazard Mater 2012, 201-202:16-22.

11. Gottschalk F, Sonderer T, Scholz RW, Nowack B: Modeled environmental concentrations of engineered nanomaterials $\left(\mathrm{TiO}_{2}, \mathrm{ZnO}, \mathrm{Ag}, \mathrm{CNT}\right.$, fullerenes) for different regions. Environ Sci Technol 2009, 43:9216-9222.

12. Kim B, Park CS, Murayama M, Hochella MF: Discovery and characterization of silver sulfide nanoparticles in final sewage sludge products. Environ Sci Technol 2010, 44:7509-7514.

13. García A, Delgado L, Torà JA, Casals E, González E, Puntes V, Font X, Carrera $J$, Sánchez A: Effect of cerium dioxide, titanium dioxide, silver, and gold nanoparticles on the activity of microbial communities intended in wastewater treatment. J Hazard Mater 2012, 199-200:64-72.

14. Choi OK, Hu ZQ: Nitrification inhibition by silver nanoparticles. Water Sci Technol 2009, 59:1699-1702.

15. Jeong E, Chae SR, Kang ST, Shin HS: Effects of silver nanoparticles on biological nitrogen removal processes. Water Sci Technol 2012, 65:1298-1303.

16. Radniecki TS, Stankus DP, Neigh A, Nason JA, Semprini L: Influence of liberated silver from silver nanoparticles on nitrification inhibition of Nitrosomonas europaea. Chemosphere 2011, 85:43-49.

17. Arnaout $\mathrm{CL}$, Gunsch CK: Impacts of silver nanoparticle coating on the nitrification potential of nitrosomonas europaea. Environ Sci Technol 2012, 46:5387-5395.

18. $\mathrm{Hu} \mathrm{Z}$ (Ed): Impact of silver nanoparticles on wastewater treatment, Final Report, Water Environment Research Foundation (WERF). Alexandria, USA: Co-published by IWA Publishing; 2010.

19. Yang $Y$, Chen $Q$, Wall JD, Hu Z: Potential nanosilver impact on anaerobic digestion at moderate silver concentrations. Water Res 2012, 46:1176-1184.

20. Tolaymat TM, El Badawy AM, Genaidy A, Scheckel KG, Luxton TP, Suidan M: An evidence-based environmental perspective of manufactured silver nanoparticle in syntheses and applications: a systematic review and critical appraisal of peer-reviewed scientific papers. Sci Total Environ 2010, 408:999-1006. 
21. Batstone DJ, Jensen PD: 4.17 - Anaerobic Processes. In Treatise on Water Science (2nd Ed). Edited by Wilderer P. Oxford, England: Academic Press (Elsevier); 2011:615-640.

22. Kiser M, Ladner D, Hristovski K, Westerhoff P: Nanomaterial transformation and association with fresh and freeze-dried wastewater activated sludge: implications for testing protocol and environmental fate. Environ Sci Technol 2012, 46:7046-7053.

23. Kiser MA, Westerhoff $P$, Benn T, Wang Y, Perez-Rivera J, Hristovski K. Titanium nanomaterial removal and release from wastewater treatment plants. Environ Sci Technol 2009, 43:6757-6763.

24. Limbach LK, Bereiter R, Mueller E, Krebs R, Gaelli R, Stark WJ: Removal of oxide nanoparticles in a model wastewater treatment plant: influence of agglomeration and surfactants on clearing efficiency. Environ Sci Technol 2008, 42:5828-5833.

25. Liu J, Pennell KG, Hurt RH: Kinetics and mechanisms of nanosilver oxysulfidation. Environ Sci Technol 2011, 45:7345-7353.

26. Cm L, Reinsch BC, Michel FM, Oumahi C, Lowry GV, Brown GE: Sulfidation processes of PVP-coated silver nanoparticles in aqueous solution: impact on dissolution rate. Environ Sci Technol 2011, 45:5260-5266.

27. Rozan TF, Lassman ME, Ridge DP, Luther GW: Evidence for iron, copper and zinc complexation as multinuclear sulphide clusters in oxic rivers. Nature 2000, 406:879-882.

28. Zhang P, Sham TK: X-Ray studies of the structure and electronic behavior of alkanethiolate-capped gold nanoparticles: the interplay of size and surface effects - reply. Phys Rev Lett 2004, 92.

29. Han S-W: Microstructural Properties of Nanostructures: Processing, Characterization and Applications. In Semiconductor Nanostructures for Optoelectronic Devices. Edited by Yi G-C. Berlin, Germany: Springer; 2012:203-209.

30. Chen LX, Liu T, Thurnauer MC, Csencsits R, Rajh T: Fe2O3 nanoparticle structures investigated by $X$-ray absorption near-edge structure, surface modifications, and model calculations. J Phys Chem B 2002, 106:8539-8546.

31. Erickson RJ, Brooke LT, Kahl MD, Venter FV, Harting SL, Markee TP, Spehar RL: Effects of laboratory test conditions on the toxicity of silver to aquatic organisms. Environ Toxicol Chem 1998, 17:572-578.

32. Klaine SJ, Bills TL, Wenholz M, La Point TW, Cobb GP, Forsythe L II: Influence of age sensitivity on the acute toxicity of silver to fathead minnows at various water quality parameters. In 4th Argentum International Conference on the Transport, Fate and Effects of Silver in the Environment; [Madison WI USA]. 1996:125-130.

33. Chen KL, Mylon SE, Elimelech M: Aggregation kinetics of alginate-coated hematite nanoparticles in monovalent and divalent electrolytes. Environ Sci Technol 2006, 40:1516-1523.

34. Pavlostathis SG, Maeng SK: Fate and effect of silver on the anaerobic digestion process. Water Res 2000, 34:3957-3966.

35. Zheng $X$, Chen $Y G$, Wu R: Long-term effects of titanium dioxide nanoparticles on nitrogen and phosphorus removal from wastewater and bacterial community shift in activated sludge. Environ Sci Technol 2011, 45:7284-7290.

36. Briee C, Moreira D, Lopez-Garcia P: Archaeal and bacterial community composition of sediment and plankton from a suboxic freshwater pond. Res Microbiol 2007, 158:213-227.

37. Youssef N, Steidley BL, Elshahed MS: Novel high-rank phylogenetic lineages within a sulfur spring (Zodletone Spring, Oklahoma), revealed using a combined pyrosequencing-sanger approach. Appl Environ Microbiol 2012, 78:2677-2688.

38. Kromkamp JC, Van Engeland T: Changes in phytoplankton biomass in the Western Scheldt Estuary during the period 1978-2006. Estuaries and Coasts 2010, 33:270-285.

39. Huber JA, Butterfield DA, Baross JA: Bacterial diversity in a subseafloor habitat following a deep-sea volcanic eruption. FEMS Microbiol Ecol 2003, 43:393-409.

40. Ikenaga M, Guevara R, Dean A, Pisani C, Boyer J: Changes in community structure of sediment bacteria along the Florida coastal everglades marsh-mangrove-seagrass salinity gradient. Microb Ecol 2010, 59:284-295.

41. Chouari R, Le Paslier D, Daegelen P, Ginestet P, Weissenbach J, Sghir A Novel predominant archaeal and bacterial groups revealed by molecular analysis of an anaerobic sludge digester. Environ Microbiol 2005, 7:1104-1115.
42. Prieur D, Troussellier M, Romana A, Chamroux S, Mevel G, Baleux B: Evolution of bacterial communities in the Gironde Estuary (France) according to a salinity gradient. Estuarine, Coastal and Shelf Science 1987, 24:95-108.

43. Cornelis G, Kirby JK, Beak D, Chittleborough D, McLaughlin MJ: A method for determining the partitioning of manufactured silver and cerium oxide nanoparticles in soil environments. Environmental Chemistry 2010, 7:298-308.

44. Cornelis G, Doolette C, Thomas M, McLaughlin MJ, Kirby JK, Beak DG, Chittleborough D: Retention and dissolution of engineered silver nanoparticles in natural soils. Soil Sci Soc Am J 2012, 76:891-902.

45. Ge HQ, Jensen PD, Batstone DJ: Increased temperature in the thermophilic stage in temperature phased anaerobic digestion (TPAD) improves degradability of waste activated sludge. J Hazard Mater 2011, 187:355-361.

46. Kunin $\mathrm{V}$, Engelbrektson $\mathrm{A}$, Ochman $\mathrm{H}$, Hugenholtz P: Wrinkles in the rare biosphere: pyrosequencing errors can lead to artificial inflation of diversity estimates. Environ Microbiol 2010, 12:118-123.

47. Engelbrektson A, Kunin V, Wrighton KC, Zvenigorodsky N, Chen F, Ochman $H$, Hugenholtz P: Experimental factors affecting PCR-based estimates of microbial species richness and evenness. ISME J 2010, 4:642-647.

48. Kunin V, Hugenholtz P: PyroTagger: a fast, accurate pipeline for analysis of rRNA amplicon pyrosequence data. The Open Journal 2010, 1:1-8.

doi:10.1186/1752-153X-7-46

Cite this article as: Doolette et al:: Transformation of PVP coated silver nanoparticles in a simulated wastewater treatment process and the effect on microbial communities. Chemistry Central Journal 2013 7:46.

Publish with ChemistryCentral and every
scientist can read your work free of charge
"Open access provides opportunities to our
colleagues in other parts of the globe, by allowing
anyone to view the content free of charge."
W. Jeffery Hurst, The Hershey Company.
- available free of charge to the entire scientific community
- peer reviewed and published immediately upon acceptance
- cited in PubMed and archived on PubMed Central
- yours - you keep the copyright
submit your manuscript here:
http://www.chemistrycentral.com/manuscript/

